\title{
PERICELLULAR COLOCALISATION AND INTERACTIVE PROPERTIES OF TYPE VI COLLAGEN AND PERLECAN IN THE INTERVERTEBRAL DISC
}

\author{
A.J. Hayes ${ }^{1}$, C.C. Shu 2 , M.S. Lord ${ }^{3}$, C.B. Little ${ }^{2,4}$, J.M. Whitelock ${ }^{3}$ and J.Melrose ${ }^{2,3,4, *}$ \\ ${ }^{1}$ The BioImaging Unit, Cardiff School of Biosciences, University of Cardiff, Cardiff, UK \\ ${ }^{2}$ Raymond Purves Bone and Joint Research Laboratory, Kolling Institute Northern Sydney Local Health District, \\ St. Leonards, Australia \\ ${ }^{3}$ School of Biomedical Engineering, University of New South Wales, Kensington, Australia \\ ${ }^{4}$ Sydney Medical School, Northern, University of Sydney, Royal North Shore Hospital, St. Leonards, Australia
}

\begin{abstract}
The aim of this study was to immunolocalise type VI collagen and perlecan and determine their interactive properties in the intervertebral disc (IVD). Confocal laser scanning microscopy co-localised perlecan with type VI collagen as pericellular components of IVD cells and translamellar cross-bridges in ovine and murine IVDs. These cross-bridges were significantly less abundant in the heparin sulphate deficient Hspg2 exon 3 null mouse IVD than in wild type. This association of type VI collagen with elastic components provides clues as to its roles in conveying elastic recoil properties to annular tissues. Perlecan and type VI collagen were highly interactive in plasmon resonance studies. Pericellular colocalisation of perlecan and type VI collagen provides matrix stabilisation and cell-matrix communication which allows IVD cells to perceive and respond to perturbations in their biomechanical microenvironment. Perlecan, at the cell surface, provides an adhesive interface between the cell and its surrounding extracellular matrix. Elastic microfibrillar structures regulate tensional connective tissue development and function. The 2010 Global Burden of Disease study examined 291 disorders and identified disc degeneration and associated low back pain as the leading global musculoskeletal disorder emphasising its massive socioeconomic impact and the need for more effective treatment strategies. A greater understanding of how the IVD achieves its unique biomechanical functional properties is of great importance in the development of such therapeutic measures.
\end{abstract}

Keywords: Perlecan, type VI collagen, pericellular matrix, extracellular matrix, mechanosensation, mechanotransduction, matrix stabilisation, translamellar cross-bridge.

*Address for correspondence:

Dr. James Melrose

Raymond Purves Bone and Joint Research Laboratories

Institute of Bone and Joint Research

Kolling Institute of Medical Research

Level 10, Kolling Building B6

University of Sydney at Royal North Shore Hospital

St. Leonards, NSW 2065

Australia

Telephone Number: +61-2-9926-4806

FAX Number: +61-2 -9926-5266

Email: james.melrose@sydney.edu.au

\section{Introduction}

The outermost region of the intervertebral disc (IVD), the annulus fibrosus (AF), contains collagenous lamellae which convey important tensile properties to the IVD (Cortes, 2014). Superior and inferior cartilaginous endplates, layers of hyaline-like cartilage at the interface of the IVD and vertebral body, and the annular lamellae enclose the central proteoglycan (aggrecan)-rich region of the IVD, the nucleus pulposus (NP) (Humzah and Soames, 1988; Shapiro, 2014). Aggrecan forms massive link-protein-stabilised ternary aggregate structures with hyaluronan (HA), which have impressive water imbibing and space-filling properties. Physical entrapment of these aggrecan macro-aggregates in the type II collagen meshwork of the NP, combined with their water imbibing properties, generates an internal hydrostatic pressure in the NP providing hydrodynamic weight bearing properties to the IVD. This entrapment process occurs both through physical containment by the random type II collagen meshwork of the NP and by interaction of the N-terminal G1 domain of aggrecan with HA and interaction of the C-type lectin domain of the C-terminus of aggrecan with a number of structural matrix proteins (Day et al., 2004; Feng et al., 2006; Olin et al., 2001). These interactions link the HA-aggrecan macroaggregates with collagenous networks to form an interactive mechanosensory network in the interstitial matrix which is linked to the pericellular matrix. Such networks are also stabilised by interactions with biglycan, decorin (Wiberg et al., 2003), matrilin-1,-3 and COMP (Fresquet et al., 2010). Type VI collagen is a major component of the chondron surrounding chondrocytes in tensional and weight bearing connective tissues (Horikawa et al., 2004; Poole et al., 1992); perlecan also has a prominent pericellular distribution (Melrose et al., 2006; Smith et al., 2010; Smith et al., 2009). Type VI collagen microfibrils interact with Von Willebrand Factor A domain-related protein (WARP) in the pericellular matrix of chondrocytes (Hansen et al., 2012) and regulate pericellular matrix properties, chondrocyte swelling, and mechanotransduction in mouse articular cartilage (Zelenski et al., 2015).

Perlecan and type VI collagen are also associated with elastic microfibrillar proteins in the IVD (Hayes et al., 2014; Hayes et al., 2011a; Hayes et al., 2011b; Hayes et al., 2013). Perlecan promotes the coacervation of tropoelastin in vitro (Hayes et al., 2011a). De novo deposition of elastin on a biochip in a quartz crystal microbalance study involved electrostatic interactions between the tropoelastin and the HS side chains of perlecan and with 
the core protein and $\mathrm{C}$-terminal region of tropoelastin (Hayes et al., 2011a). HS chains have been shown to regulate $\mathrm{N}$ - and $\mathrm{C}$-terminal interactions in fibrillin-1 (Cain et al., 2008), which result in the retention of fibrillin-1 microfibrils at the cell surface (Bax et al., 2007); this is aided by an Arg-Gly-Asp (RGD) sequence in fibrillin and an RGD sequence in perlecan domain III which are interactive with cell surface integrins (Bax et al., 2007; Jovanovic et al., 2007; McGowan et al., 2008; Midwood and Schwarzbauer, 2002). This facilitates the assembly of elastic microfibrils at the cell surface; fibrillin- 1 is the major component of elastin microfibrils (Kielty et al., 2005; Kielty et al., 2002b). Microfibrils are assembled by head to tail attachment of fibrillin-1 molecules and lateral associations of the microfibrils into multimeric assemblies to support the coacervation of tropoelastin (Hayes et al., 2011a) within these structures (Kielty et al., 2002a; Kielty et al., 2002c). These fibrillar assemblies are large enough to be visualised by light microscopy while the monomeric microfibrils require electron microscopy for visualisation (Kielty et al., 2002a; Kielty et al., 2005; Kielty et al., 2002b; Kielty et al., 2002c; Sherratt et al., 2003). Fibrillin microfibrils provide viscoelastic properties to tissues (Ritty et al., 2002), aid in the anchorage of cells in the matrix (Bax et al., 2007; Jovanovic et al., 2007; McGowan et al., 2008; Midwood and Schwarzbauer, 2002) and equip cells with mechanosensation (Kielty et al., 2002a; Kielty et al., 2005; Kielty et al., 2002b; Kielty et al., 2002c; Sherratt et al., 2003), important in tissue function and cellular responsiveness which regulates tissue homeostasis in health and disease (Hubmacher et al., 2006; Jordan et al., 2006; Jovanovic et al., 2007; Kielty et al., 2002a; Kielty et al., 2002c; Ramirez et al., 2008; Ramirez and Dietz, 2007; Ramirez et al., 2007).

HS and integrin-mediated interactions of fibrillin regulate microfibrillar assembly and cellular adhesion; $\alpha \mathrm{V} \beta 3, \alpha 5 \beta 1$ and $\alpha \mathrm{V} \beta 6$ integrins all interact with fibrillin-1 displaying high (Kd $40 \mathrm{nM})$, moderate $(\mathrm{Kd} 450 \mathrm{nM})$ and low (Kd $11 \mathrm{M})$ binding affinities, respectively (Jovanovic et al., 2007). $\alpha \mathrm{V} \beta 3$ Integrin regulates microfibril assembly in periodontal ligament (Tsuruga et al., 2009), and along with $\alpha 5 \beta 1$ integrin the activation of human umbilical vein endothelial cells (Mariko et al., 2010) and lung fibroblasts (McGowan et al., 2008), mediating cell signalling, cellular proliferation and cytoskeletal reorganisation which regulates cell migration.

Elastic microfibrils are found at strategic locations between adjacent lamellae and within translamellar crossbridges, which provide elastic recoil properties to the collagenous lamellae (Kielty et al., 2002a; Kielty et al., 2005; Kielty et al., 2002b; Li et al., 2012; Midwood and Schwarzbauer, 2002; Yu, 2002; Yu et al., 2005; Yu et al., 2015; Yu et al., 2007; Yu et al., 2002). Latent transforming growth factor $\beta$ (LTGF $\beta$ ) binding proteins-1, 2 (LTBPs $1,2)$ are also associated with fibrillin-1 in microfibrils. Besides their structural roles in the extracellular matrix (ECM), LTBPs are key regulators of mesenchymal cell function (Davis et al., 2014; Kan et al., 2015). LTBP-2 is the only member of the fibrillin superfamily which does not sequester TGF- $\beta 1$ within tissues; however, it competes with LTBP-1 for the same binding sites on fibrillin- 1 and thus it may modulate TGF- $\beta 1$ deposition in tissues (Hirani et al., 2007). LTBP-2 also competes with tropoelastin for binding to fibulin-5, negatively regulating elastogenesis (Sideek et al., 2014). LTBP-2 has multiple HS binding sites (Parsi et $a l ., 2010$ ) and colocalises with perlecan in the IVD (Hayes et al., 2014). LTBP-2 has a single high-affinity binding site for fibroblast growth factor 2 (FGF-2) and blocks FGF-2induced cell proliferation (Menz et al., 2015) countering the HS-mediated cell proliferative properties of perlecan with FGF-2 (Knox et al., 2002).

No studies have so far demonstrated the relative distributions of type VI collagen and perlecan in the IVD or their interactive properties. The present study addressed this deficiency and demonstrated interactive properties between type VI collagen and perlecan expected to convey important functional properties to the IVD in ECM organisation and stabilisation, cell-matrix and cellcell communication, and regulation of tissue homeostasis.

\section{Materials and Methods}

\section{Materials}

Rat monoclonal anti-perlecan domain-IV (A7L6) (ab2501) and rabbit anti-type VI collagen (ab6588) polyclonal antibodies were obtained from Abcam through Sapphire Bioscience (Waterloo, NSW, Australia). A rabbit polyclonal antibody to perlecan (CCN-1) was produced in-house against purified human endothelial perlecan. Antibodies against heparan sulphate (HS) (clone F58-10E4) and heparinase (Hep) III generated HS stubs (clone F69-3G10), chondroitinase $\mathrm{ABC}$ and heparitinase III (EC 4.2.2.8) were purchased from Seikagaku Corp. (Tokyo, Japan). Monoclonal anti-chondroitin-sulphate (CS) (clone CS56) was from Sigma-Aldrich (St. Louis, MO, USA). Mouse monoclonal CS stub antibodies (MAb 2B6, MAb 3B3) were gifts from Prof. Bruce Caterson (Cardiff University, Cardiff, UK). Rabbit anti type VI collagen (RDI-600401-108) for Western blotting was from Fitzgerald Industries International (North Acton, MA, USA). Alexa 594-conjugated donkey anti-rat and Alexa 488-conjugated goat anti-rat IgG secondary antibodies were obtained from Molecular Probes (Eugene, OR, USA). Purified clostridial collagenase (CLSPA) was obtained from Worthington Industries through ScimaR (Templestowe, Victoria, Australia).

\section{Tissues}

The sheep used in this study $(n=6)$ were pedigree Merino wethers (castrated males) aged 18 months. C57BL6 Wild type and Hspg2 exon 3 null mice were obtained from our breeding colonies at the Kearns animal facility, Royal North Shore Hospital. Appropriate clearances were obtained from our institutional ACEC for the experiments described.

\section{Histological processing of IVD tissues}

IVD-vertebral body segments were fixed in $10 \%$ neutral buffered formalin for $48 \mathrm{~h}$ then decalcified in $10 \%$ formic acid, $5 \%$ neutral buffered formalin (7-10 d). A central 4-5 $\mathrm{mm}$ thick vertical mid-sagittal slab was cut and 
dehydrated in graded alcohols and xylene and the specimen double embedded in celloidin-paraffin.

Lumbar spinal segments of 3 week old C57BL6 Wild type and Hspg2 exon 3 null mice were fixed $24 \mathrm{~h}$ in $10 \%$ neutral buffered formalin and decalcified in $10 \%$ formic acid, $5 \%$ neutral buffered formalin for $72 \mathrm{~h}$ and embedded in paraffin using standard histological procedures. Serial parasagittal longitudinal sections were cut at $4 \mu \mathrm{m}$ for histological examinations.

\section{Bright-field immunolocalisation of type VI collagen in murine IVDs}

Sections were de-waxed in xylene, washed in Tris-buffered saline (TBS) and primary antibody (1/100 dilution), rabbit anti-type VI collagen, applied overnight at $4{ }^{\circ} \mathrm{C}$ using a Sequenza apparatus. The specimens were then blocked for $1 \mathrm{~h}$ in Dako non-protein block and horseradish peroxidase-conjugated goat anti-rabbit IgG secondary antibody (1/1000 dilution) was applied for $3 \mathrm{~h}$ at room temperature. After washing in TBS, diaminobenzidine was added for the colour development step for $30 \mathrm{~min}$ at room temperature. The slides were then counterstained with Harris' haematoxylin, coverslipped, and examined by brightfield microscopy utilising a Leica DFC 480 digital photomicroscope.

\section{Laser scanning confocal microscopy}

Ovine IVD sections $(7 \mu \mathrm{m})$ were de-waxed in xylene and rehydrated, digested with $0.4 \mathrm{U} / \mathrm{mL}$ chondroitinase $\mathrm{ABC}$ in $100 \mathrm{mM}$ Tris acetate buffer $(\mathrm{pH} 6.8)$ for $1 \mathrm{~h}$ at $37^{\circ} \mathrm{C}$, then blocked with normal donkey serum (1:20 dilution) for $30 \mathrm{~min}$ at room temperature. An anti-perlecan rat $\mathrm{mAb}$ (A7L6; 1:50 dilution) was then incubated on the sections overnight at $4{ }^{\circ} \mathrm{C}$. Sections were washed, and an Alexa594-conjugated donkey anti-rat second antibody (1:200 dilution) was applied for $1 \mathrm{~h}$ at room temperature. After washing, sections were again blocked with normal goat serum (1:20 dilution) for $30 \mathrm{~min}$ at room temperature before incubation with a rabbit anti-type VI collagen polyclonal antibody (VIB; 1:500 dilution) for $3 \mathrm{~h}$ at room temperature. Sections were washed before application of an Alexa 488-conjugated goat anti-rabbit (1:200 dilution) secondary antibody for $1 \mathrm{~h}$ at room temperature. After a final wash, sections were mounted under coverslips in Vectashield mountant containing DAPI (Vector Laboratories, Peterborough, UK). Fluorescently stained tissue sections were visualised using a Leica TCS SP2 AOBS laser scanning confocal microscope (Leica, Heidelberg, Germany) using $\times 40$ and $\times 63$ oil immersion objectives. To avoid spectral cross-talk between fluorochromes, samples were sequentially scanned using excitation and emission settings for sequential recordings of DAPI (Ex. max: 359; Em. max: 461), Alexa 488 (Ex. max: 488; Em max: 520) and Alexa 594 (Ex. max 594; Em max: 618). Z-stacks of 8-bit 'optical sections' $(512 \times 512$ pixels $)$ were taken through the full thickness of tissue sections at between 0.4 and $0.6 \mu \mathrm{m}$ increments. 'Maximum Intensity'-type reconstructions were prepared from the image stacks using Leica Confocal Software (Leica, Heidelberg, Germany) or Voxx 2 (written by Jeffrey L. Clendenon (Clendenon et al., 2002); http://www.nephrology.iupui.edu/imaging/voxx).

\section{Colocalisation analysis}

Alexa 488 and Alexa 594-labeled perlecan and type VI collagen immunolocalisations were compared in single confocal optical sections using algorithms (described below) that were either built into the Leica Confocal Software or freeware plug-ins for Image J public domain Java image processing (http://rsb.info.nih.gov/ij/).

\section{Colocalisation overlays}

Regions of red-green co-localisation were demonstrated using the ImageJ co-localisation highlighter plug-in (written by Pierre Bourdoncle, Institut Jacques Monod, Service Imagerie, Paris, France; http://rsb.info.nih.gov/ ij/plugins/co-localization.html). Two points in the image were considered co-localised if their respective voxel intensities (0-255) were higher than the threshold value (50.0) of their channels and if the ratio of their intensity was higher than the ratio setting value (50\%). Applying these criteria, regions of red-green co-localisation were highlighted using a white overlay mask superimposed upon the original RGB image.

\section{Intensity profiles}

Leica Confocal Software (Leica, Heidelberg, Germany) was used to compare voxel intensity profiles obtained from arbitrary line segments that were drawn across individual cells and their surrounding ECM for both red and green channels. The resultant plots were used to assess similarities in both the distribution and intensity of fluorescent staining of perlecan (red) and type VI collagen (green). For each plot the horizontal axis represents line distance in $\mathrm{mm}$ and the vertical axis voxel intensity (scale of 0-255).

\section{$3 D$ contour profiles}

$3 \mathrm{D}$ contour plots of voxel intensity data $(0-255)$ from both red and green channels were rendered spatially as height in a 3D contour plot using the Image $J$ interactive 3D Surface Plot plug-in (written by Kai Uwe Barthel, htw-berlin.de, Internationale Medieninformatik, Berlin, Germany; http:// rsb.info.nih.gov/ij/plugins/surface-plot-3d.html).

\section{Isolation of ovine IVD perlecan}

Pooled IVDs (L1-L2 to L6-L7) of two ovine lumbar spines were dissected into AF and NP, and these tissues separately extracted with $4 \mathrm{M} \mathrm{GuHCl}, 50 \mathrm{mM}$ Tris- $\mathrm{HCl}$, pH 7.2 containing $10 \mathrm{mM}$ EDTA, $10 \mathrm{mM}$ benzamidine, $5 \mathrm{mM}$ N-ethylmaleimide and $50 \mathrm{mM}$ 6-aminohexanoic acid (10 $\mathrm{mL}$ extraction buffer/g tissue wet weight) using end-over-end mixing for $48 \mathrm{~h}$ at $4{ }^{\circ} \mathrm{C}$. The tissue residue was spun down and discarded, and the extracts equilibrated in $6 \mathrm{M}$ urea, $50 \mathrm{mM}$ Tris- $\mathrm{HCl}, \mathrm{pH} 7.2$ and clarified using a $0.22 \mu \mathrm{m}$ membrane. The extracts $(30 \mathrm{~mL})$ were chromatographed on a Hiload 26/10 preparative column of Q-Sepharose using an AKTA explorer chromatography system eluting at a flow rate of $12 \mathrm{~mL} / \mathrm{h}$ and $3 \mathrm{~mL}$ fractions were collected. The column was washed with 2 bed volumes of starting buffer ( $50 \mathrm{mM}$ Tris- $\mathrm{HCl}, \mathrm{pH} 7.2,6 \mathrm{M}$ urea, buffer A) till a steady baseline was achieved. Bound perlecan was eluted with a linear $0-2.0 \mathrm{M}$ gradient of $\mathrm{NaCl}$ in buffer A over 7 bed volumes. Protein (A280 nm) and 
sulphated glycosaminoglycan (GAG) were monitored in each fraction; an in-line conductivity meter monitored the progress of the gradient. Most of the GAG (aggrecan) eluted at 1-2 $\mathrm{M} \mathrm{NaCl}$ and was discarded. The fractions eluting between 0.1-0.3 M NaCl (fractions 20-25) contained perlecan species identified by dot blotting; these fractions were pooled and concentrated over a $100 \mathrm{kDa}$ membrane by centrifugal ultrafiltration. The perlecan pools from anion exchange were examined by Superose 6 HR10/30 FPLC. The column was eluted at $15 \mathrm{~mL} / \mathrm{h}$ with $50 \mathrm{mM}$ Tris-HCl, $\mathrm{pH} 7.2,0.15 \mathrm{M} \mathrm{NaCl}, 0.5 \mathrm{~mL}$ fractions were collected, and protein was monitored by A280 nm. Fractions $14-17$ were subsequently pooled as purified perlecan and used for the BIAcore plasmon resonance studies. SDS-PAGE and Western blotting verified the purity of the perlecan preparations.

\section{Purification of native collagen VI from ovine cornea}

Frozen ovine corneas in liquid nitrogen were freeze shattered to a fine powder by pulverisation in a stainless steel mortar and pestle and resuspended in $10 \mathrm{~mL}$ of $50 \mathrm{mM}$ Tris-HCl, pH 7.5, 150 mM NaCl, 5 mM EDTA, 1 \% (v/v) Nonidet P-40, $0.1 \%$ (w/v) CHAPS (NET buffer) containing $1 \mathrm{mM}$ 4-(2-aminoethyl) benzenesulfonyl fluoride, $20 \mathrm{mM}$ $N$-ethylmaleimide protease inhibitors. After incubation at $4{ }^{\circ} \mathrm{C}$ for $2 \mathrm{~h}$, insoluble material was pelleted by centrifugation $(15,000 \times g$ for $5 \mathrm{~min})$ and the pellet was washed twice with NET buffer and twice with $50 \mathrm{mM}$ Tris$\mathrm{HCl}, \mathrm{pH} 7.5,400 \mathrm{mM} \mathrm{NaCl}, 10 \mathrm{mM} \mathrm{CaCl}_{2}$ (collagenase buffer). The insoluble material was resuspended in collagenase buffer $(10 \mathrm{~mL})$ containing 2500 units of collagenase (CLSPA, Worthington Biochemical Corp., Lakewood, NJ, USA) and 1300 units of hyaluronidase per g of cornea, $1 \mathrm{mM}$ 4-(2-aminoethyl) benzenesulfonyl fluoride, and $20 \mathrm{mM} N$-ethylmaleimide. The samples were digested for $20 \mathrm{~h}$ at room temperature, insoluble material was removed from the preparation by centrifugation (15000 $\times g$ for $5 \mathrm{~min}$ ), and the clarified extract stored at $4{ }^{\circ} \mathrm{C}$. One $\mathrm{mL}$ of collagenase-digested ovine cornea was loaded onto a Sepharose CL2B column $\left(100 \times 1.6 \mathrm{~cm}^{2}\right)$ pre-equilibrated in $50 \mathrm{mM}$ Tris- $\mathrm{HCl}, \mathrm{pH} 7.5,150 \mathrm{mM} \mathrm{NaCl}$ and $5 \mathrm{mM}$ EDTA, and eluted at a flow rate of $0.5 \mathrm{~mL} / \mathrm{min}$ collecting $3.0 \mathrm{~mL}$ fractions on a Frac 100 fraction collector using an AKTA explorer chromatography system. Eluant fractions were monitored at $280 \mathrm{~nm}$ and by BCA protein analysis. The void volume peak fractions were examined by 3-8 \% Tris acetate gradient SDS-PAGE and the gels stained with Coomassie R250 and blotted to nitrocellulose for Western and dot blotting to identify the type VI collagen containing fractions, which were pooled and concentrated by centrifugal diafiltration over a $10 \mathrm{kDa}$ cut-off membrane and the buffer exchanged into phosphate-buffered saline (PBS). The protein values of concentrated samples were measured against bovine serum albumin (BSA) as standard and stored frozen $\left(-20^{\circ} \mathrm{C}\right)$.

\section{Surface plasmon resonance}

Surface plasmon resonance experiments were performed using BIAcore 2000 (BIAcore AB, Uppsala, Sweden) optical biosensor with research-grade gold sensor chips. Binding experiments between perlecan immobilised on the sensor chips and collagen type VI were conducted in PBS, $\mathrm{pH} 7.4$, at $20^{\circ} \mathrm{C}$. Immunopurified perlecan from human coronary artery endothelial cells (HCAEC) and perlecan purified from IVD was diluted in PBS to $20 \mu \mathrm{g} / \mathrm{mL}$ and coupled to gold sensor chips at a flow rate of $5 \mu \mathrm{L} / \mathrm{min}$. A similar amount of each purified perlecan was immobilised to the gold chips in each case as determined from the change in response units. BSA $(0.1 \mathrm{w} / \mathrm{v} \%)$ in PBS $(5 \mu \mathrm{L} /$ $\mathrm{min}$ ) was exposed to the surface for $20 \mathrm{~min}$ to block nonspecific binding sites before rinsing with PBS at a flow rate of $20 \mu \mathrm{L} / \mathrm{min}$ for $10 \mathrm{~min}$. Collagen type VI $(20 \mu \mathrm{g} /$ $\mathrm{mL}$ ) was then exposed to the sensor surface at a flow rate of $20 \mu \mathrm{L} / \mathrm{min}$ for $5 \mathrm{~min}$. The experiments were repeated with immunopurified perlecan treated with Hep III and IVD perlecan treated with both chondroitinase $A B C$ and Hep III. Sensograms were analysed using BIAcore 2000 evaluation software 3.0. Binding experiments between perlecan immobilised on the sensor chips and collagen type VI were also conducted in the presence of perlecan peptides. Immunopurified endothelial perlecan treated with Heparinase III was coupled to gold sensor chips at a flow rate of $5 \mu \mathrm{L} / \mathrm{min}$. Bovine serum albumin $(0.1 \mathrm{w} / \mathrm{v} \%)$ in PBS ( $5 \mu \mathrm{L} / \mathrm{min}$ ) was exposed to the surface for $20 \mathrm{~min}$ to block nonspecific binding sites before rinsing with PBS at a flow rate of $20 \mu \mathrm{L} / \mathrm{min}$ for $10 \mathrm{~min}$. Collagen type VI $(20 \mu \mathrm{g} / \mathrm{mL})$ was pre-mixed with one of the perlecan peptides $(10 \mu \mathrm{g} / \mathrm{mL})$ for $10 \mathrm{~min}$ prior to exposure to the immobilised perlecan at a flow rate of $20 \mu \mathrm{L} / \mathrm{min}$ for $5 \mathrm{~min}$. The experiments were repeated using collagen type VI premixed with perlecan antibodies $(5 \mu \mathrm{g} / \mathrm{mL})$ instead of the peptides. Antibodies to perlecan domain I (A76), domainIII (7B5) and domain-IV (A7L6) were used.

\section{Endoglycosidase digestion}

Samples were digested with $50 \mathrm{mU} / \mathrm{mL}$ proteinase free chondroitinase $\mathrm{ABC}$ in $0.1 \mathrm{M}$ Tris acetate, $\mathrm{pH} 8$, at $37^{\circ} \mathrm{C}$ for $16 \mathrm{~h}$ to determine the presence of CS. Samples were also digested with $50 \mathrm{mU} / \mathrm{mL}$ Hep III in $10 \mathrm{mM}$ Tris- $\mathrm{HCl}$, $\mathrm{pH} 7.4$, at $37^{\circ} \mathrm{C}$ for $16 \mathrm{~h}$ to establish the presence of HS.

\section{Western blotting}

Purified perlecan samples $(10 \mu \mathrm{g} /$ lane $)$ were treated with heparinase III $(0.01 \mathrm{U} / \mathrm{mL})$ or chondroitinase ABC $(0.05 \mathrm{U} / \mathrm{mL})$ in Dulbecco's phosphate-buffered saline (DPBS), $\mathrm{pH} 7.2$, at $37^{\circ} \mathrm{C}$ for $16 \mathrm{~h}$, and electrophoresed through 3-8 \% Tris-Acetate NuPAGE ${ }^{\circledR}$ SDS-PAGE gels (Invitrogen, Carlsbad, CA, USA) for $1 \mathrm{~h}$ at $200 \mathrm{~V}$ in TrisTricine buffer (50 mM Tricine, $50 \mathrm{mM}$ Tris base, $0.1 \%$ w/v SDS, pH 8.3). Molecular weight standards (HiMark ${ }^{\circledR}$, Invitrogen) were also electrophoresed on each gel. Samples were then transferred to polyvinylidene difluoride (PVDF) membrane (Immobilon-P, Millipore, Billerica, MA, USA) using transfer buffer ( $5 \mathrm{mM}$ Bicine, $5 \mathrm{mM}$ Bis Tris, $0.2 \mathrm{mM}$ EDTA, $0.005 \%$ SDS, $10 \% \mathrm{v} / \mathrm{v}$ methanol, $\mathrm{pH}$ 7.2) in a semi-dry blotter at $300 \mathrm{~mA}$ and $20 \mathrm{~V}$ for $1 \mathrm{~h}$. The membrane was blocked with $1 \% \mathrm{w} / \mathrm{v}$ BSA in TBS for $2 \mathrm{~h}$ at room temperature, followed by incubation with rabbit $\mathrm{pAb} C \mathrm{CN}$ 1 to perlecan diluted 1:10,000 in $1 \% \mathrm{w} / \mathrm{v}$ BSA-TBS for $16 \mathrm{~h}$ at room temperature. Membranes were subsequently rinsed with TBS, incubated with horseradish peroxidase (HRP)-conjugated goat anti-rabbit IgG antibodies 

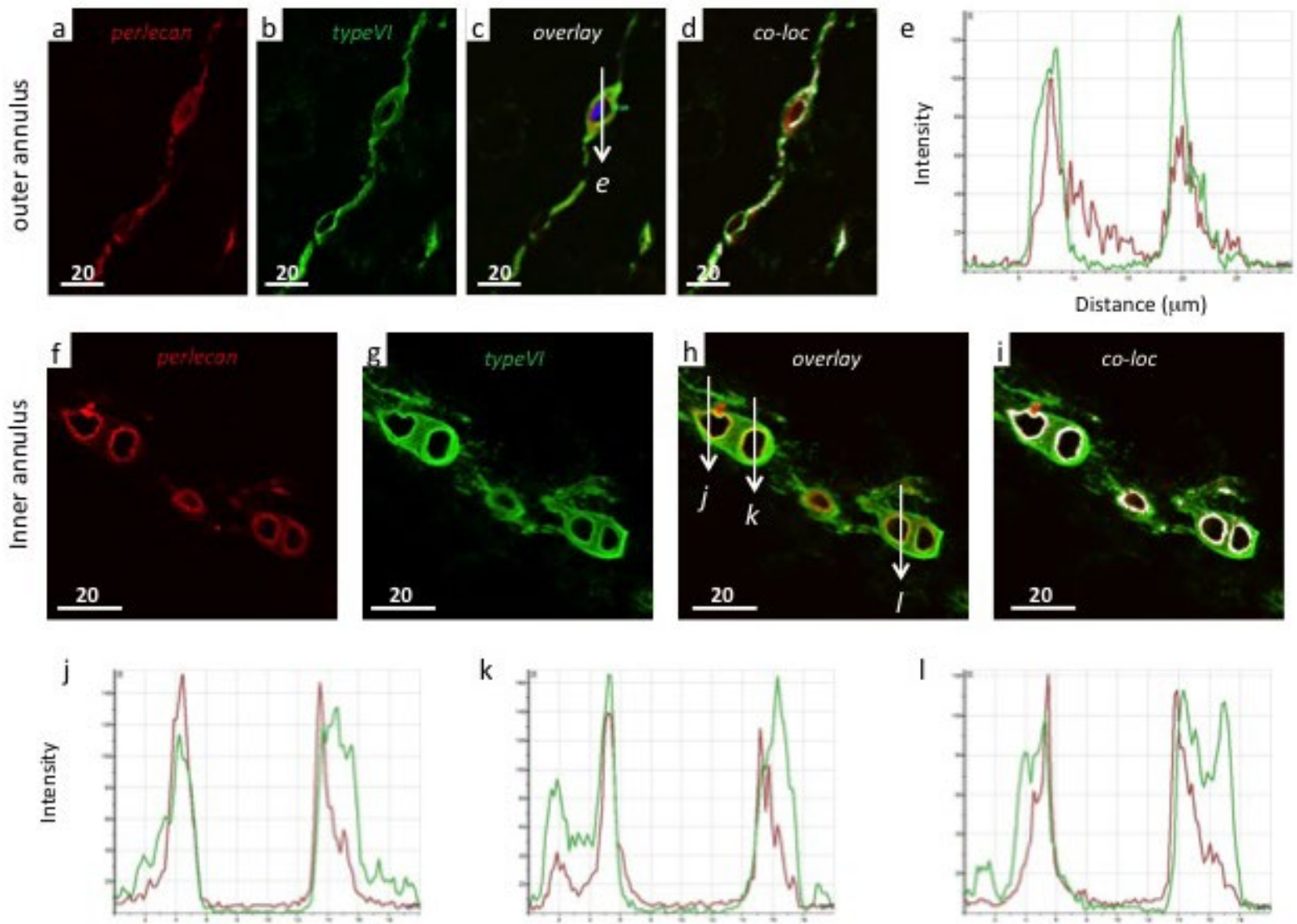

Distance $(\mu \mathrm{m})$

Fig. 1. Dual localisation of perlecan (MAb A7L6) (a) and type VI collagen (b) around outer annulus fibrosus cells (a-e) and inner annulus fibrosus cells (f-l) by fluorescent confocal microscopy using Alexa 594 and 488 labelled secondary antibodies for visualisation. The perlecan-type VI collagen colocalisations are also presented as merged images $(\mathbf{c}, \mathbf{h})$ to demonstrate co-localisation and voxel overlays used to define co-localised regions (d,i). Image intensity plots through selected cells are also presented to demonstrate the localisation of perlecan and type VI collagen (e, j-l). Scale bars indicated in $\mu \mathrm{m}$.

$(1: 50,000)$ for $45 \mathrm{~min}$ at room temperature, and rinsed in TBS before being imaged using chemiluminescent reagents (Femto reagent kit, Pierce Biotechnology, Rockford, IL, USA) and X-ray film (Australian Imaging Distributors, North Ryde, NSW, Australia).

\section{Results}

Dual fluorescent confocal immunolocalisations of perlecan and type VI collagen in IVD tissue sections demonstrated their discrete colocalisation in the pericellular matrix immediately adjacent to the disc cell margins in the outer (Fig. 1a-e) and inner AF (Fig. 1f-l) and NP (Fig. 2a-k). Type VI collagen had a more extensive distribution pattern extending further from the cell margins to the edge of the chondron surrounding the disc cells (Fig. 2g), whereas perlecan was more closely associated with the cell margins (Fig. 2f). Type VI collagen also linked strings of cells in the outer AF located along the major axis of the type I collagen fibre bundles laid down in the annular lamellae (Fig. 1b). This was also evident to a lesser extent around the cells of the inner AF (Fig. 1g), however in the NP cells type VI collagen and perlecan were discretely colocalised to the pericellular matrices around the margins of individual cells (Fig. 2h, k). Overlays of the co-localised areas of perlecan and type VI collagen immunolocalisation were calculated using Voxel 2 software to clearly demonstrate the areas of co-localisation (Fig. 1d, Fig. 1i, Fig. 2d, Fig. 2i), and image intensity profiles measured across cells of interest in a given field of view to further confirm the distributions of the fluorescent labels for perlecan and type VI collagen around selected cells of interest (Fig. 1e, Fig. 1j-1, Fig. 2e, j). Three dimensional intensity plots were also determined for a selected NP cell (Fig. 2k) from the perlecan and type VI collagen immunolocalisations (Fig. 2f, g), co-localisation (Fig. 2h) and voxel overlay image data (Fig. 2i). This clearly delineated areas of colocalisation, and confirmed the calculated image intensity profiles (Fig. 2e, f).

Primary ovine IVD cells were grown in short term monolayer culture for $4 \mathrm{~d}$ to examine the perlecan they synthesised. Perlecan was laid down as a fine fibrillar network, this attached the cells to the tissue culture plastic and networked the disc cells (Fig. 3a, g). This network was substituted with HS identified by MAb 3G10 to the HS stubs (Fig. 3e, k) and with MAb 10E4 to native HS (Fig. 3f, l). Fibronectin (Fig. 4c, i) and laminin (Fig. 3d, j) were also detected pericellularly, but their deposition was 

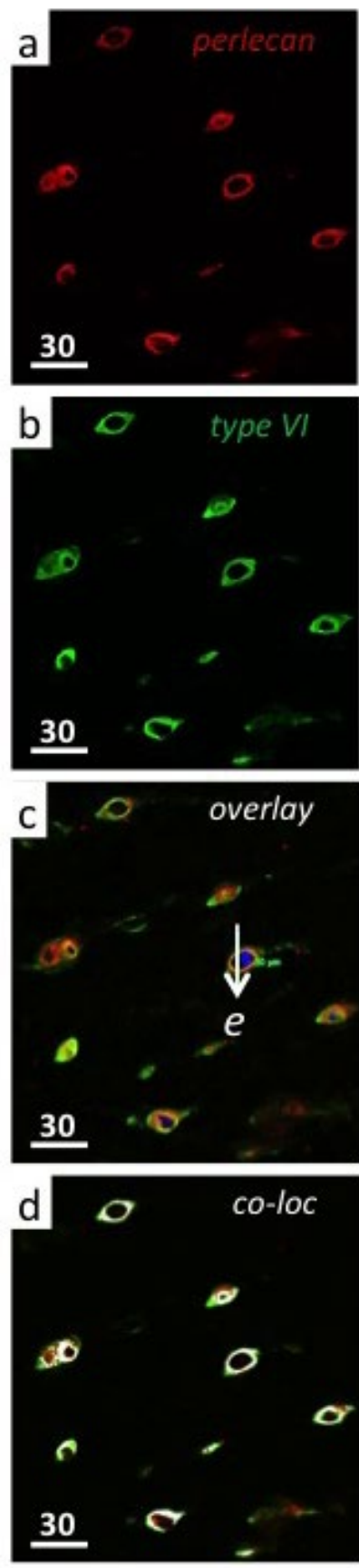

e

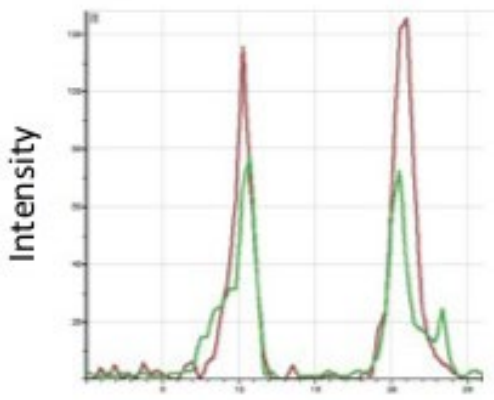

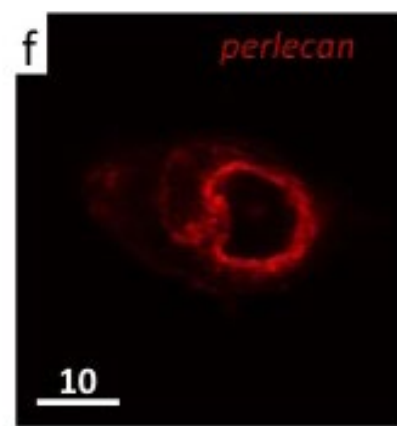
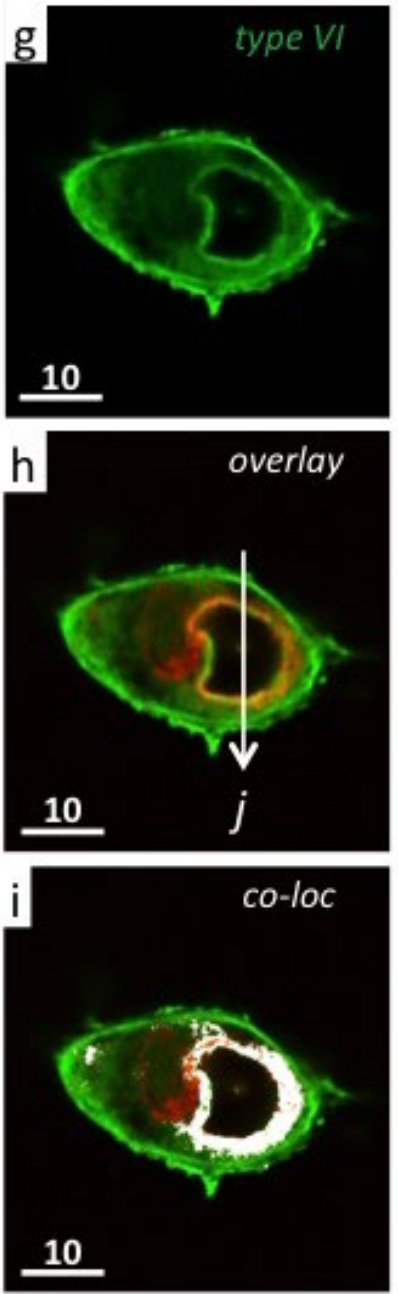

j

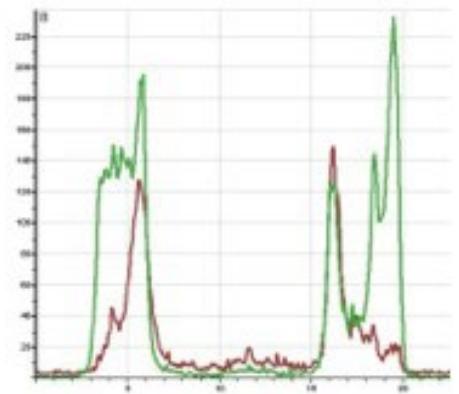

Distance $(\mu \mathrm{m})$

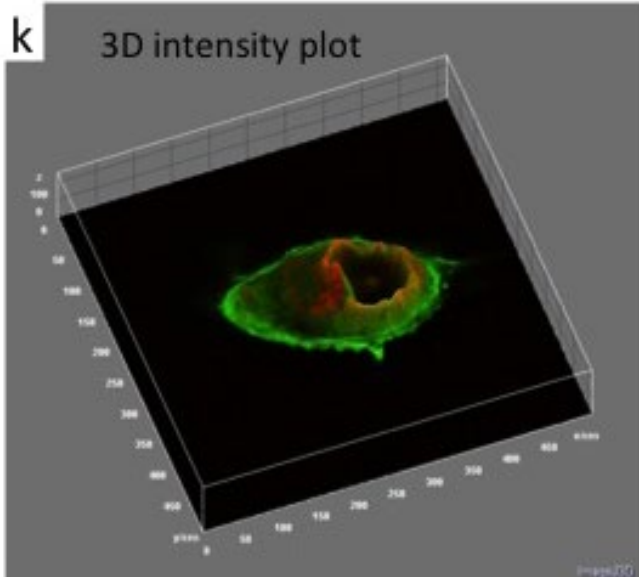

Fig. 2. Dual localisation of perlecan (MAb A7L6) (a,f) and type VI collagen $(\mathbf{b}, \mathbf{g})$ around nucleus pulposus cells by fluorescent confocal microscopy using Alexa 594 and 488 labelled secondary antibodies for visualisation. The perlecan-type VI collagen colocalisations are also presented as merged images $(\mathbf{c}, \mathbf{h})$ to demonstrate co-localisation and voxel overlays used to define co-localised regions (d,i). Image intensity plots through a selected cell are also presented to demonstrate the localisation of perlecan and type VI collagen $(\mathbf{e}, \mathbf{j})$ and a 3D intensity plot through the $\mathrm{x}, \mathrm{y}$ and $\mathrm{z}$ axes $(\mathbf{k})$. Scale bars indicated in $\mu \mathrm{m}$. 

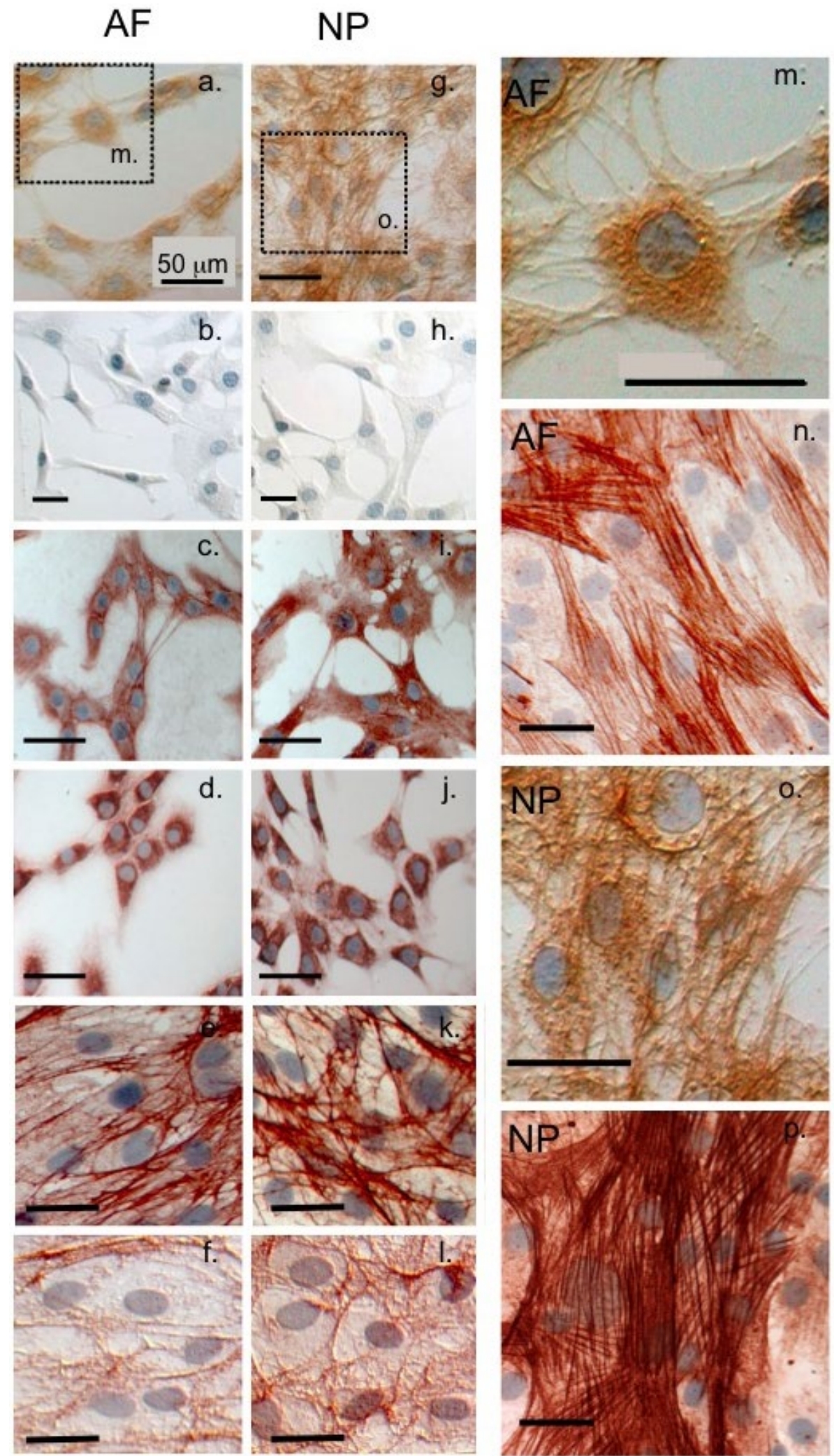

Fig. 3. Comparative immunolocalisation of perlecan (a,g,m,o), fibronectin (c,i), laminin (d,j), MAb $3 \mathrm{G} 10 \Delta \mathrm{HS}$ unsaturated stub epitope $(\mathbf{e}, \mathbf{k})$, native HS (f,l) and smooth muscle cell $\alpha$-actin $(\mathbf{n}, \mathbf{p})$ synthesised by 4 d primary monolayer cultures of AF (a-f,m,n) and NP cells $(\mathbf{g}-\mathbf{l}, \mathbf{0}, \mathbf{p})$. Perlecan localisation was undertaken using anti domain-I perlecan antibody A76 (a,g,m,o), fibronectin using a pan-fibronectin Ab (c,i), laminin using a pan-laminin Ab (d,j). Plates (e) and (k) were predigested with heparitinase III to generate the $\Delta \mathrm{HS}$ stub epitopes identified by MAb $3 \mathrm{G} 10$, while in plates (f) and (I) no predigestion was used with MAb 10E4 to native HS. The boxed areas in (a) and (g) are displayed at higher magnification in plates (m) and (o). Actin stress fibre formation by the AF and NP cells grown in monolayer culture are visualised in plates (n) and (p), respectively. Cell nuclei were counterstained with haematoxylin. All scale bars are $50 \mu \mathrm{m}$. Diaminobenzidine was used as chromogen in plates $(\mathbf{a}, \mathbf{g}, \mathbf{m}, \mathbf{o})$ and Nova RED was used in all other plates. Negative control plates for the AF and NP cultures are presented in (b) and (h), respectively. 


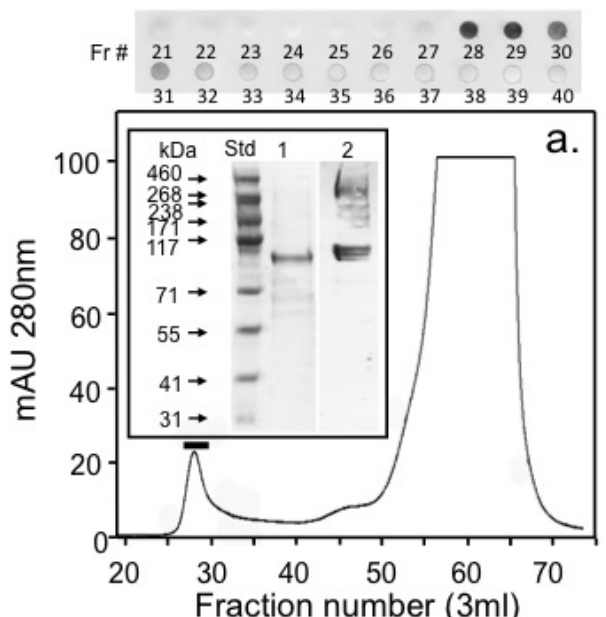

Fraction number (3ml)

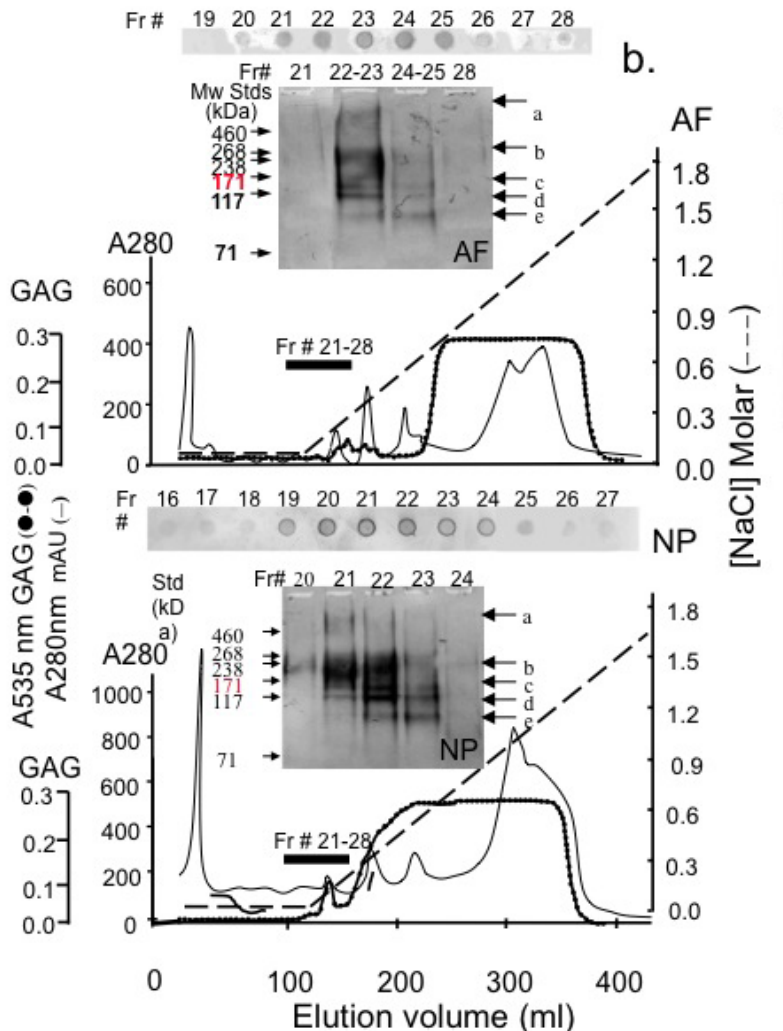

Elution volume (ml)

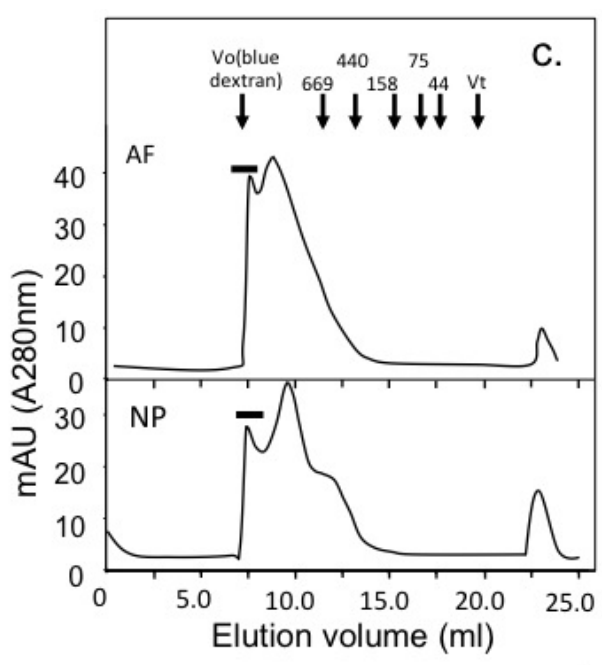

d.
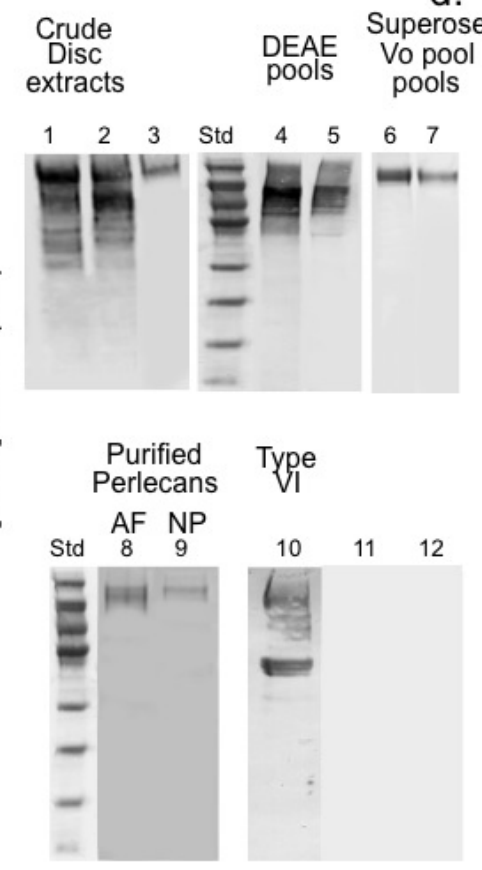

Fig. 4. (a) Isolation of type VI collagen tetramers from corneal extracts as collagenase resistant macromolecular material voiding a Sepharose CL2B column. SDS-PAGE of an aliquot of pooled fractions 26-30 stained with Coomassie R250 (inset) and confirmation of type VI collagen in eluant fractions by dot blotting. Fractions 26-30 were subsequently pooled from four runs as a source of purified type VI collagen for use in Biacore plasmon resonance studies. (b) Isolation of perlecan from extracts of AF and NP tissue by DEAE Sepharose anion exchange chromatography employing gradient elution. The insets in (b) represent perlecan identified by Western and dot blots of individual fractions using pAb CCN-1. Under the elution conditions employed, fractions 20-26 contained the perlecan samples of interest, which were pooled and concentrated prior to examination by Superose 6 size exclusion FPLC. (c) Superose 6 FPLC of the perlecan anion exchange pool. The barred area represents the perlecan sample subsequently used for Biacore plasmon resonance studies. Elution fraction numbers are indicated with small arrows at the top of the figure as are the elution positions of blue dextran 2000 which was used to indicate the void volume (Vo) of the column and large molecular weight protein standards, thyroglobulin, bovine thyroid $(669 \mathrm{kDa})$, ferritin, horse spleen (440 kDa), catalase, bovine liver $(232 \mathrm{kDa})$, aldolase, rabbit muscle $(158 \mathrm{kDa})$, transferrin $(75 \mathrm{kDa})$, and ovalbumin, chicken $(44 \mathrm{kDa})$. (d) Western blotting of $\mathrm{GuHCl}$ extracted AF and NP perlecan samples (lanes 1,2), anion exchange AF and NP chromatography pools $($ lanes 4,5$)$, and Superose 6 pools (lanes 6,7 ). A sample of affinity purified human umbilical vein endothelial cell perlecan (HUVEC, lane 3 ) is also shown. Prestained molecular weight standards (Novex see blue 2) are indicated in the Std lane. Lanes 8-12 depict 3-8 \% gradient SDS-PAGE of Superose 6 FPLC pools of the AF and NP perlecan samples (lanes 8, 9, 11, 12) and purified type VI collagen (lane 10) visualised by Western blotting using anti perlecan domain IV (MAb A7L6) (lanes 8,9) and anti-type VI collagen antibody (lanes 10-12) demonstrating a lack of type VI collagen reactivity in the purified perlecan samples (lanes 11, 12). 
a. Perlecan peptides used in competitive binding

\begin{tabular}{|c|c|c|c|c|}
\hline Peptide & Domain & Amino acids & Sequence & Peptide identity \\
\hline 1 & II & 216-232 & EYRCDRRPDCRDMSDEL & LDL receptor \\
\hline 2 & II & 295-310 & GHCIPRDYLCDGQEDC & LDL receptor class $\mathrm{A} 2$ \\
\hline 3 & III & $851-868$ & CESCAPGYEGNPIQPGGK & Laminin EGF-like 3 \\
\hline 4 & IV & $3521-3537$ & TWSKVGGHLRPGIVQSG & Ig-like C2 type \\
\hline 5 & V & $3965-3981$ & LLFSGGKSGPVEDFVS & Laminin G-like 2 \\
\hline
\end{tabular}

b. IVD perlecan

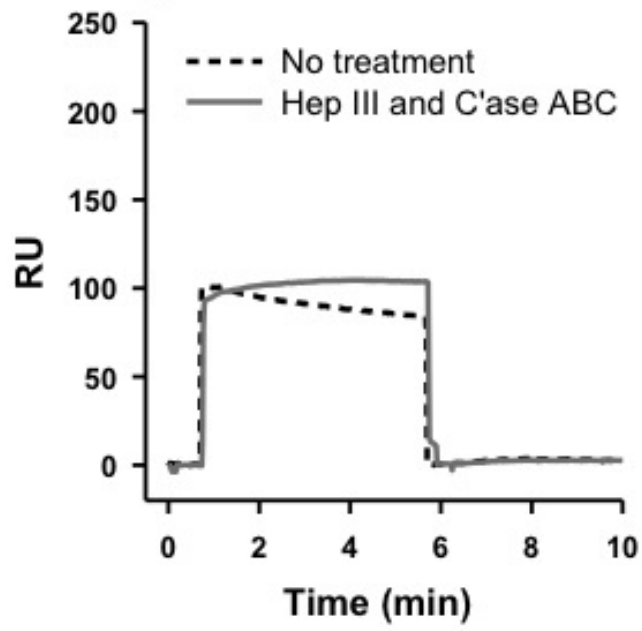

d. Competitive binding
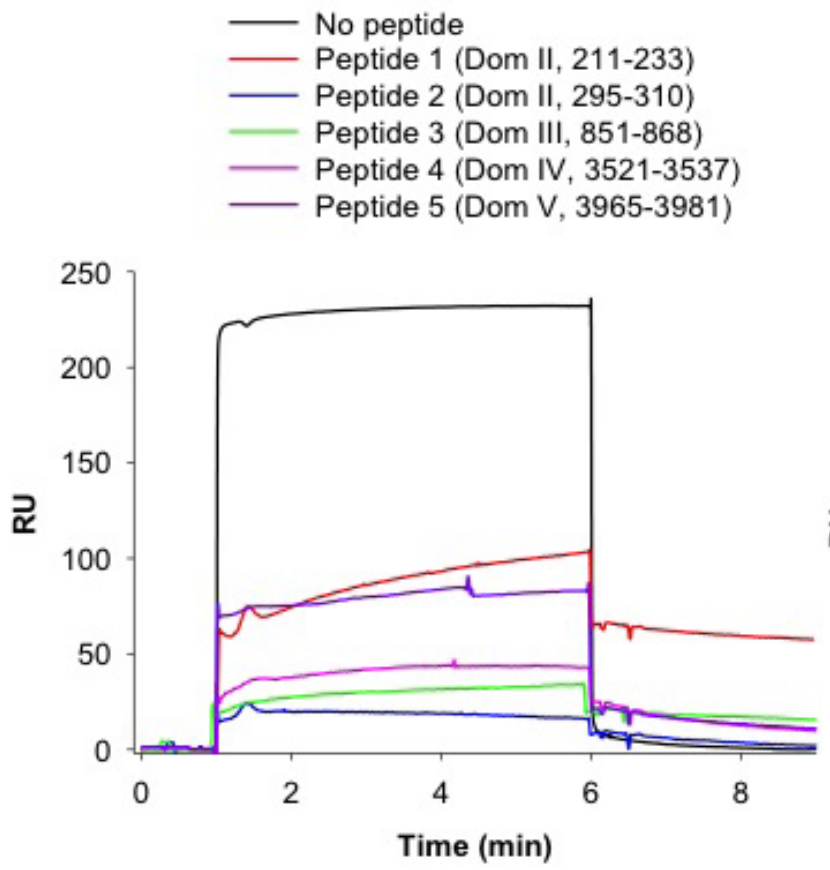

\section{HCAEC perlecan}

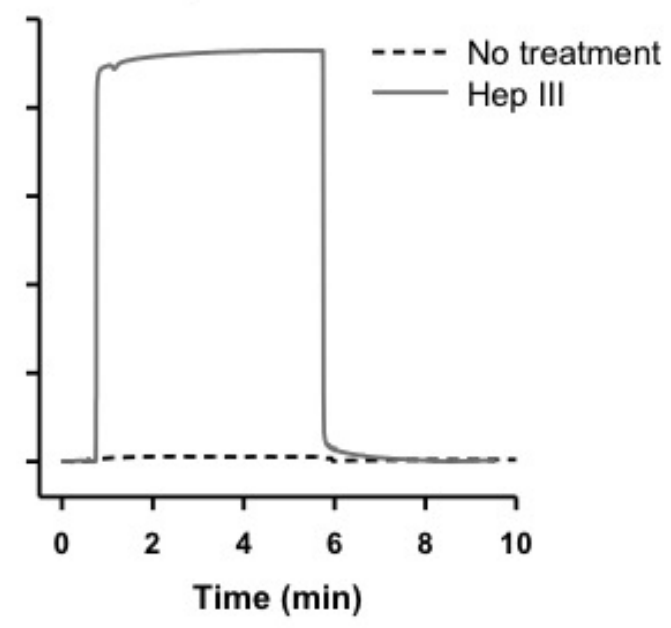

e. Perlecan Dom I and III Ab Inhibit binding

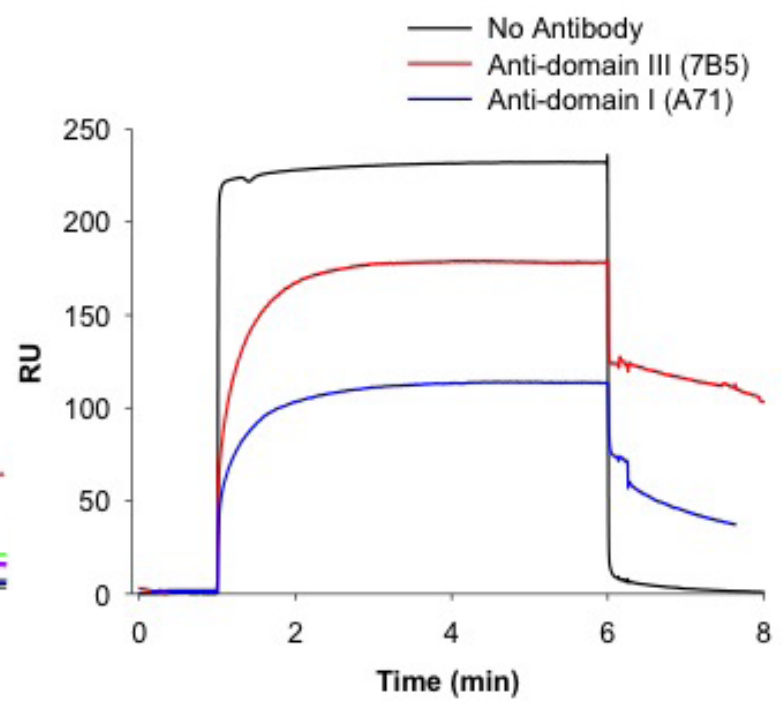

Fig. 5. Plasmon resonance studies of the interaction of the HCAEC and disc perlecan and corneal type VI collagen. Information on peptides derived from perlecan domains II, III, IV and V which were used as competitive substrates in the type VI collagen-perlecan interactions is provided in (a). Interaction of ovine IVD perlecan (b) and HCAEC perlecan (c) with type VI collagen, and competitive binding of selected perlecan peptide fractions (d) and antibodies to perlecan domain I and III (e). The peptides were pre-incubated with type VI collagen before applying the mixture to immobilised HCAEC perlecan (pre-digested with heparanase III) on a chip. Peptides 2, 3 and 4 from domains III and IV of perlecan were more inhibitory than peptides 1 and 5. The results indicate that the HS chains in domain I of perlecan inhibit the interaction of collagen VI-perlecan. This interaction is instantaneous and involves multiple interactive binding sites along the perlecan core protein in all its five domains. 

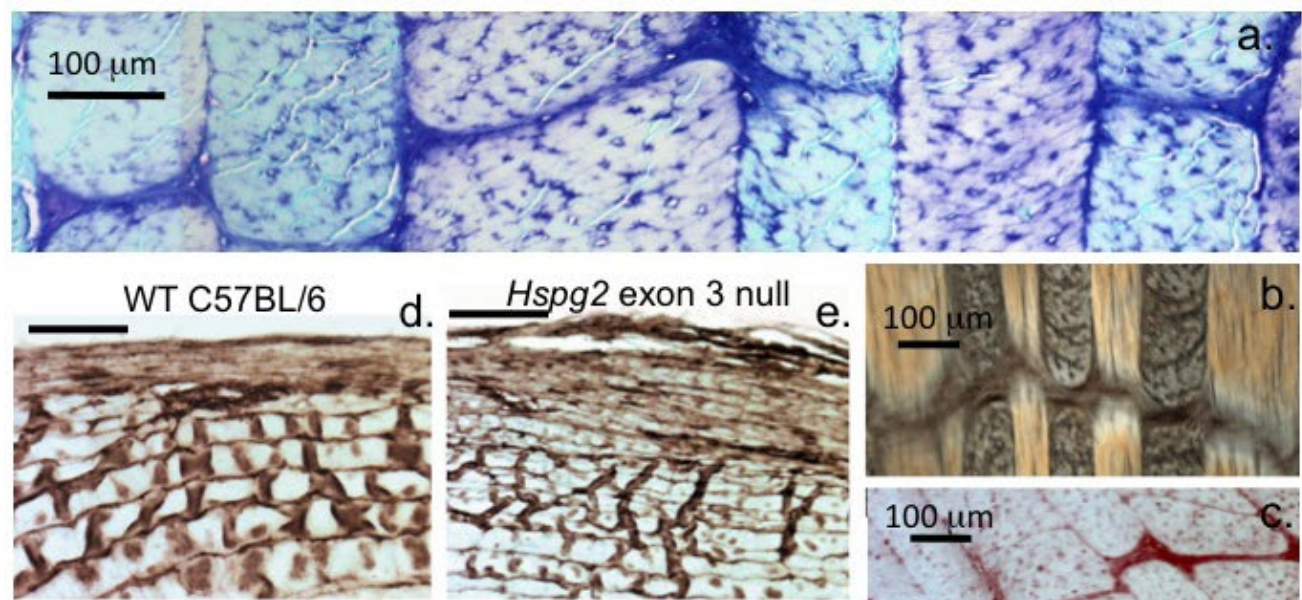

Hspg2 exon 3 null
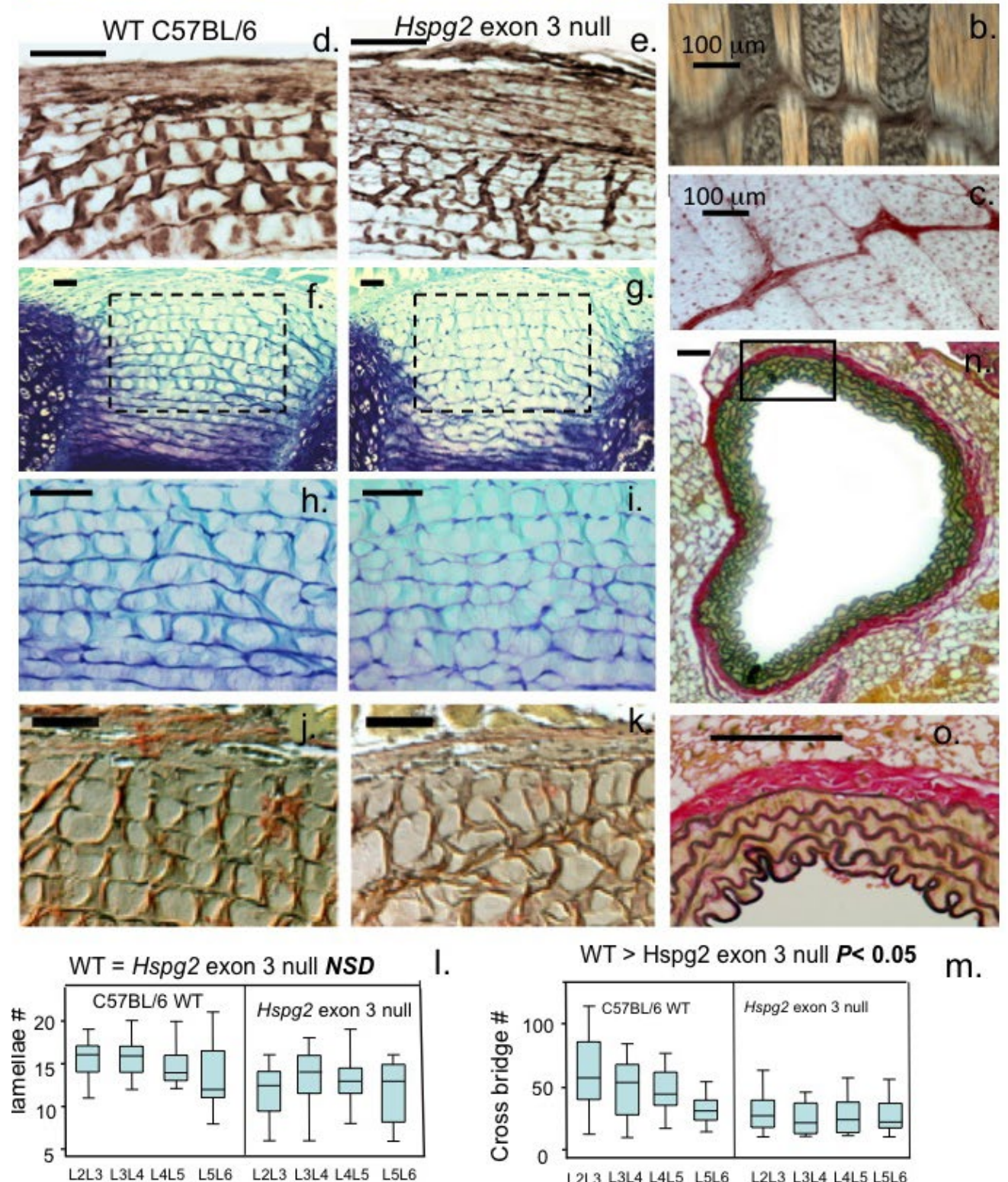

I.

WT $>$ Hspg2 exon 3 null $P<0.05$

$\mathrm{m}$.

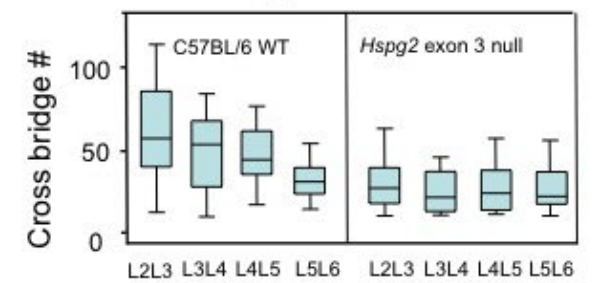

Fig. 6. Demonstration of type VI collagen as a component of translamellar cross-bridge networks in 1 year old toluidine blue stained, Nomarski imaged and type VI collagen immunolocalised ovine (a-c) and 3 week old murine IVDs (d-k). A cross-section of a murine aorta (n,o) was used as a positive control tissue for the Van Geissen elastic stain, the boxed area in (n) is presented at higher magnification in (o) where five elastic lamellae are clearly evident in the intima. Van Geisen elastic stain visualises elastic structures in translamellar cross-bridges in C57BL/6 wild type (WT) (j) and Hspg2 exon 3 null HS deficient murine AF (k) using Nomarski DIC imaging and is consistent with the type VI collagen immunolocalisations in vertical sections of WT (d) and Hspg2 exon 3 null HS deficient murine AF (e). Translamellar cross-bridges visualised by toluidine blue depict proteoglycan deposition in these structures, ovine AF (a) and murine AF (f,g,h,i). Nomarski DIC imaged ovine cross-bridge (b). The number of annular lamellae (l) and translamellar crossbridges (m) were counted by morphometric image analysis of WT and Hspg2 exon 3 null mouse IVDs and quantified by 2 blinded observers using a scoring scheme established for murine IVD histopathology. Lamellae numbers were similar for both genotypes (I). WT mice had significantly more annular cross-bridges than the Hspg2 exon 3 null mice $(p<0.05)$ in the L2-L3, L3-L4 and L4-L5 IVDs. Box plots showing median, upper and lower quartile (box), 10-90 $0^{\text {th }}$ percentile (whiskers), and maximum and minimum values of the translamellar cross-bridge numbers and number of lamellae in murine IVDs. Differences between groups were assessed using nonparametric analysis (Mann-Whitney U test), $p<0.05$ considered significant. Scale bars shown are $100 \mu \mathrm{m}$. 


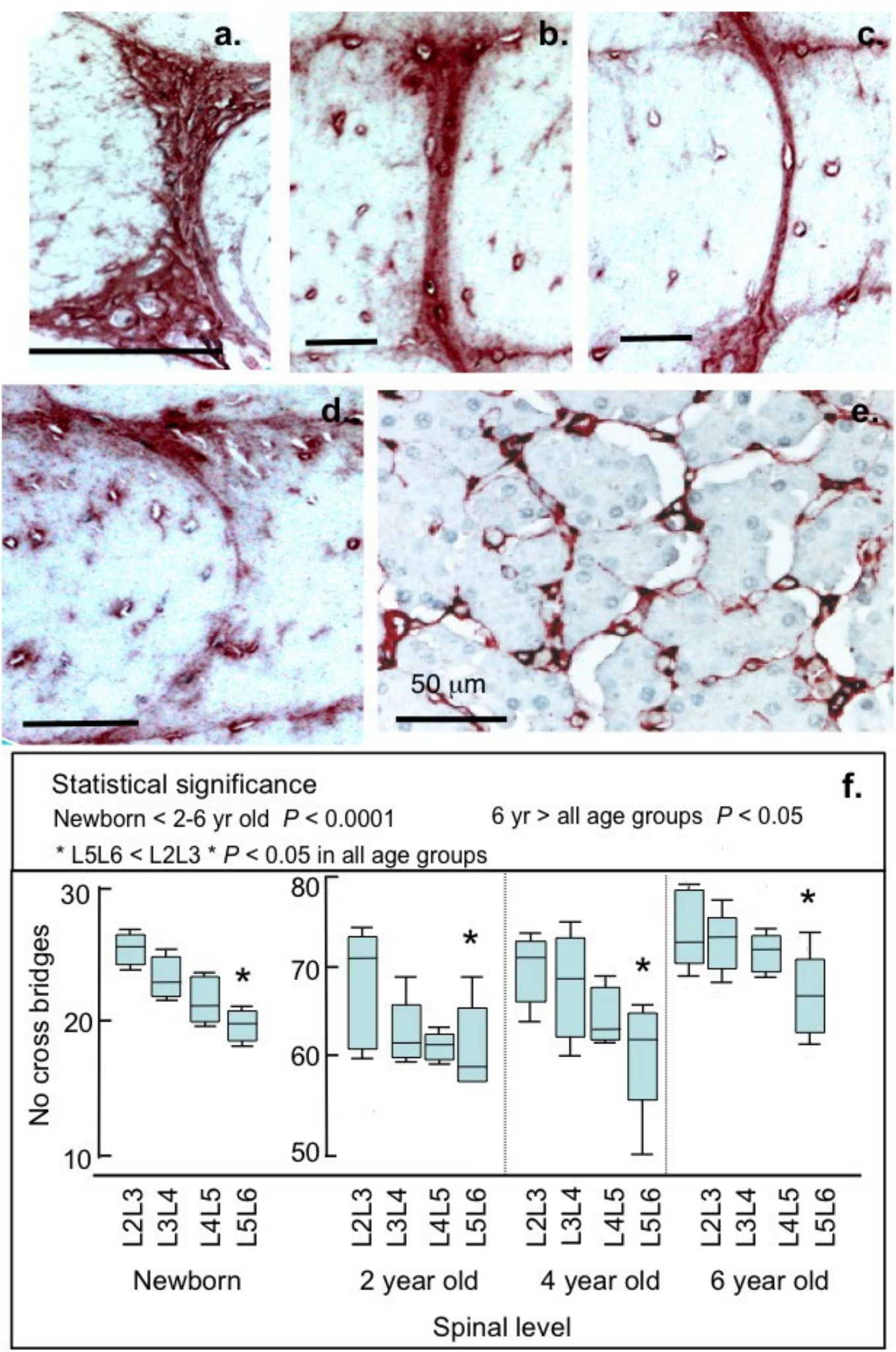

Fig. 7. Immunolocalisation of type VI collagen to translamellar cross-bridges in newborn (a), 2 year (b), 4 year (c) and 6 year old (d) ovine intervertebral discs; chromogen NovaRED. Ovine pancreas positive control (e). Scale bars $50 \mu \mathrm{m}$ (a-e). Quantitation of the annular cross-bridge numbers in L2-L3 to L5-L6 IVDs in 5 sheep per age group (f). Crossbridge numbers were significantly lower in the newborn sheep group compared to the other sheep groups $(p<0.0001)$. Spinal level dependant trends in cross-bridge numbers were also evident with the L2-L3 IVDs having higher numbers and the L5-L6 IVDs the lowest in the 2-6 year old sheep groups; however, these values were only significant in the L4-L5 and L5-L6 IVDs of the 6 year sheep group which were higher than all other L4-L5 and L5-L6 IVDs examined $(p<0.05)$. Box plots showing median, upper and lower quartile (box), 10-90 th percentile (whiskers), and maximum and minimum values of the translamellar cross-bridge numbers and number of lamellae in newborn, 2 and 6 year-old sheep IVDs. Differences between groups were assessed using nonparametric analysis (Mann-Whitney $\mathrm{U}$ test), $p<0.05$ considered significant. 
not as extensive as perlecan. Higher power images clearly showed the fine perlecan positive fibrillar material in the pericellular matrix of the AF (Fig. 3m) and NP cells (Fig. 3o). The AF and NP cells elaborated an extensive actin cytoskeleton consistent with their elongation in culture (Fig. 3n, p).

Corneal type VI collagen was isolated from ovine corneas using collagenase digestion and the tissue extract separated on a column of Sepharose CL2B (Fig. 4a). Dot blotting of aliquots of individual fractions confirmed the distribution of the type VI collagen peak that eluted in the void volume fractions. Further analysis of these pooled fractions by Western blotting using specific antibodies to type VI collagen and protein staining (Fig. 3a, inset) confirmed the identity and purity of the type VI collagen so isolated. Ovine intervertebral disc perlecan was isolated by $4 \mathrm{M} \mathrm{GuHCl}$ extraction from the tissue, equilibration of the extract in DEAE anion exchange buffer ( $6 \mathrm{M}$ urea $50 \mathrm{mM}$ Tris- $\mathrm{HCl}, \mathrm{pH} 7.2,0.1 \mathrm{M} \mathrm{NaCl}$ ), and separation of the extract by anion exchange chromatography on DEAE Sepharose employing gradient elution (0.1-2 M $\mathrm{NaCl}$ in starting buffer) (Fig. 4b). Perlecan eluted early in the $\mathrm{NaCl}$ gradient at $\sim 0.25 \mathrm{M} \mathrm{NaCl}$, well separated from aggrecan and versican, the major disc proteoglycans which eluted at $\sim 0.8-1.5 \mathrm{M} \mathrm{NaCl}$. Western blotting of individual fractions using perlecan-specific antibodies (MAb A7L6) subsequently identified perlecan eluting in fractions 20-28 under the conditions we employed (Fig. 4b, inset). Samples of the DEAE perlecan pools were subsequently examined by Superose 6 size exclusion chromatography (Fig. 4c). Fractions eluting in the void volume were examined by SDS-PAGE and protein staining (Fig. 4d, lanes 8 and 9) and Western blotting to be full-length perlecan of high purity (Fig. 4d, lanes 6 and 7). The perlecan preparations did not cross-react with antibodies to type VI collagen (Fig. 3d, lanes 11 and 12). The purity of the corneal type VI collagen preparation isolated was also confirmed by Western blotting (Fig. 4d, lane 10).

BIAcore surface plasmon resonance was conducted on full-length perlecan, perlecan fragments and type VI collagen (Fig. 5a, b). This demonstrated rapid interaction between these components in vitro, but only after prior removal of HS chains using pre-digestion with heparitinase III (Fig. 5c). The HS chains on human HCAEC perlecan inhibited the interaction with type VI collagen (Fig. 5c), but this was not apparent with the purified disc perlecan that contained no detectable HS or CS (Fig. 5b). Competitive binding fragments of perlecan from domains II, III, IV or $\mathrm{V}$ inhibited the interaction of full-length perlecan with type VI collagen to variable degree (Fig. 5d), as did specific antibodies to perlecan domain I (MAb A71) or domain III (MAb 7B5) (Fig. 5e). This indicated that the interaction between perlecan and type VI collagen had a rapid multipoint attachment mechanism involving many regions of the perlecan core protein. IVD perlecan bound collagen type VI to a similar extent in both its untreated state and after treatment with endoglycosidases, but displayed $\sim 50 \%$ of the response compared to HCAEC perlecan (Fig. 5b). The interaction between HCAEC perlecan and collagen type VI was inhibited by the presence of HS (Fig. 5c). HCAEC perlecan that had been treated with heparanase III bound twice as much type VI collagen as IVD perlecan, even though the same amount of perlecan was coated on the BIAcore chip. The association rate of collagen type VI to each perlecan was similar with equilibrium achieved instantaneously. The dissociation rate was marginally slower for collagen type VI on heparanase III-predigested HCAEC perlecan than any of the other test conditions. Thus the binding characteristics of collagen type VI to endothelial and IVD perlecan differed. Binding was only conducted at one concentration thus it was not possible to calculate binding constants.

A histological examination of the role of type VI collagen in the structural organisation of the IVD indicated that besides being a prominent pericellular matrix component, type VI collagen was also a prominent component of the translamellar cross bridging networks in ovine (Fig. 6a-c) and murine IVDs (Fig. 6d-k). The appearance of these bridges differed between the ovine and murine IVDs; proteoglycan was a more predominant component of the ovine cross bridges (Fig. 6a) and these could also be visualised using Nomarski optics (Fig. 6b) and readily detected immunohistochemically using antibodies to type VI collagen (Fig. 6c, d, e). The annular cross bridges were less prominent in the Hspg2 exon 3 null mice (Fig. 6g, i). The van Geissen elastic stain was particularly useful for the delineation of the cross bridges in the murine IVDs, which presumably reflects their relative content of elastic fibre components (Fig. 6d, e). The murine aorta was a useful positive control tissue for the elastic van Geissen stain, with the elastic layers clearly defined by this staining procedure (Fig. 6n, o). The numbers of annular lamellae and annular cross bridges were manually counted in mid-sagittal longitudinal lumbar spinal sections in the C57BL6 wild type and Hspg2 exon null mice (Fig. 6l, m). The number of annular lamellae did not vary between the two genotypes, however the number of cross-bridges showed a decreasing trend towards the L5-L6 IVD in the wild type but not the Hspg2 null mouse IVDs (Fig. 61, m) and this was statistically significant $(p<0.05)$. Closer inspection of the translamellar cross-bridges in the lumbar ovine IVDs also showed age and spinal level dependant trends in their abundance (Fig. $7 \mathbf{a}-\mathbf{d}, \mathbf{f}$ ). The relative size of the cross-bridges decreased significantly with advancing age, which was clearly evident in immunolocalisations conducted with an anti-type VI collagen antibody (Fig. $7 \mathbf{a}-\mathbf{d})$. The numbers of cross-bridges decreased in number in the lumbar spinal segments, with a significant decrease in the 2-6 year old IVDs at comparable spinal levels to the newborn sheep IVDs (Fig. 7f). There was also a decreasing trend in cross-bridge numbers when progressing down the spine to the lower lumbar IVDs (L5-L6), with the L5-L6 IVD having the lowest numbers of cross-bridges at all age points of the IVDs examined (Fig. 7f). The relative numbers of cross-bridges were significantly higher in the murine IVDs compared to the ovine lumbar IVDs, with average numbers ranging from $30-80$ in the murine wild type IVDs compared to $18-75$ in the ovine IVDs. Thus the density of the cross-bridges was significantly higher in the murine IVDs and similar to the relative cell densities in these tissues. 


\section{Discussion}

A number of publications have shown that pericellular matrix components have biomechanical functions in tensional and weight bearing connective tissues (Cao et al., 2007; Cao et al., 2009; Cao et al., 2011; Darling et al., 2010; Guilak et al., 2006; McLeod et al., 2013; Wilusz et al., 2012). Evidence from theoretical modelling and experimental studies shows that the pericellular matrix receives biomechanical signals that regulate cellular metabolism in tensional and weight bearing connective tissues. The present study has shown type VI collagen is a major component of the chondron (Horikawa et al., 2004; Poole et al., 1992) as is perlecan (Melrose et al., 2006); however, no comparative studies have specifically demonstrated their specific distributions within the disc cell chondron. Type VI collagen was present in an extended region extending away from the cell to the margins of the chondron interconnecting rows of cells aligned along the collagen fibre bundles in the outer AF and to a lesser extent in the inner AF, but was not observed in the NP where it formed a discrete pericellular matrix around individual NP cells. In articular cartilage, atomic force microscopy shows that pericellular localisation of perlecan provides compliancy to the type VI collagen lattices encompassing the chondrocyte (Wilusz et al., 2012). Type VI collagen is a transducer of biomechanical and/ or biochemical signals originating in the ECM (Guilak et al., 2006) via coupled interactive networks between the pericellular matrix and link protein-stabilised aggrecanHA or versican-HA networks (Day et al., 2004; Feng et al., 2006; Fresquet et al., 2010; Olin et al., 2001; Wiberg et al., 2003). The contributions type VI collagen makes to tissue function is obvious in type VI collagen knockout mice, where knee and hip articular cartilage develop osteoarthritis (OA) (Doane et al., 1998) and tendons have diminished biomechanical capability. Type VI collagen has binding sites for integrins which connect the cell to its biomechanical microenvironment (Burg et al., 1996) including $\alpha 1 \beta 1, \alpha 2 \beta 1, \alpha 10 \beta 1$ and $\alpha 11 \beta 1$; disc cells express $\alpha 1 \beta 1$ integrin and $\alpha 1, \alpha 2, \alpha 5, \alpha \mathrm{V}, \beta 1, \beta 3$ and $\beta 5$ subunits (Burg et al., 1996). Pericellular CSPG4, a $250 \mathrm{kDa}$ proteoglycan, is considered a type VI collagen receptor (Burg et al., 1996; Doane et al., 1998; Nishiyama and Stallcup, 1993; Stallcup et al., 1990; Tillet et al., 2002).

In monolayer cultures of disc cells, the pericellular matrix contained fine fibrillar perlecan positive material; fibronectin and laminin deposition was less extensive. The disc cells also displayed an extensive actin cytoskeleton facilitating cellular extension and cell spreading. Perlecan is interactive with cell adhesive proteins, cell surface integrins and structural ECM glycoproteins (Whitelock et al., 2008) providing cell-matrix and cell-cell interconnections. Type VI collagen also interacts with cell surface integrins facilitating cell-matrix interconnection and communication (Horikawa et al., 2004; Tulla et al., 2001; Zelenski et al., 2015). In the present study, interaction between perlecan and type VI collagen using surface plasmon resonance demonstrated rapid multi-point interactions involving all five domains of perlecan. LTBP-2 also displays pericellular colocalisation with perlecan in IVD tissues (Hayes et al.,
2014) and contains a single high affinity FGF-2 binding site (Menz et al., 2015). Disulphated CS chains on growth plate perlecan direct collagen fibrillogenesis (Kvist et al., 2006). Perlecan in the human foetal spine is substituted with HS (Shu et al., 2013b) and the 7D4 CS sulphation motif (Shu et al., 2013a), but with tissue maturation this epitope becomes virtually undetectable. Type VI collagenrich translamellar cross-bridges in the IVD interconnect up to 18 lamellar layers (Melrose et al., 2008; Schollum et al., 2010; Yu et al., 2015). The precise role of these translamellar cross-bridges is unclear; however, the interconnections they provide and presence of elastic components in the cross-bridges suggests a supportive role in disc tissues. The fact that cross-bridge numbers vary along the lumbar spine and with ageing indicates their assembly is responsive to intrinsic spinal biomechanical forces. The cross-bridges may provide resiliency to the collagenous lamellae. Collagen fibrils are inextensible and once loaded are incapable of returning to their prestressed dimensions, thus the elastic components in the cross-bridges may provide recoil properties.

The IVD provides mechanical stability during axial and torsional loading and spinal flexibility during flexion and extension and absorbs and dissipates spinal forces preventing these concentrating in the lower lumbar regions, an unfortunate consequence of the erect human posture. Supraphysiological loading of the IVD leads over time to the development of disc degeneration and the development of low back pain (LBP). As seen in the present study, the highly interactive properties of type VI collagen and perlecan provide matrix stabilisation. Perlecan also provides cohesive properties to the cell-ECM interface contributing to cell-matrix communication and the ability of the disc cell to perceive and respond to changes in its biomechanical microenvironment. Disc cells are exposed to a hostile environment of low oxygen tension, high lactic acid levels, low nutrition and a high hydrostatic pressure leading to cell death and a diminution in cell numbers over time due to cellular senescence (Vo et al., 2016; Wang et al., 2016), apoptosis (Kermani et al., 2014; Kuo et al., 2014) and autophagy (Gruber et al., 2015; Ma et al., 2013). Thus, it is important that measures are in place to protect the disc cell and maintain the composition of IVD tissues. Type VI collagen and perlecan both form part of these protective measures. Even so, an age-dependant decline occurs in IVD cell numbers to such an extent that the remaining cells are incapable of adequately replenishing ECM components to maintain tissue homeostasis and optimal mechanical stability. The subsequent degenerative changes in the IVD, which ensue eventually, result in the generation of low back pain in $\sim 40 \%$ of degenerate IVDs. The Global Burden of Disease study of 2010 identified LBP as the number one global musculoskeletal condition (Hoy et al., 2014a; Hoy et al., 2010; Hoy et al., 2014b; Maniadakis and Gray, 2000; Vos et al., 2012; Walker et al., 2003) with major socioeconomic impact. There is, therefore, a strong imperative for the development of effective treatment strategies for LBP. A greater understanding of how the IVD achieves its unique biomechanical properties is very useful background information in the development of such therapeutic measures. 


\section{Conclusions}

Perlecan and type VI collagen are important interactive components of the disc cell pericellular matrix; their diverse range of interactive partners and ability to form network structures between cell and matrix reinforce their importance in mechanosensory and cell regulatory functions which affect cellular survival and tissue homeostasis.

\section{Acknowledgements}

This study was funded by NHMRC (Australia) Project Grant 352562. AJH undertook the confocal microscopy, evaluated data, helped in manuscript writing and reviewed the final version. CCS undertook a number of the experimental procedures, anion and size exclusion chromatography, isolation of perlecan and type VI collagen, surface plasmon resonance, data collection, and analysis and manuscript review. MSL contributed to experimental design, supervised the plasmon resonance and ELISA data collection, and helped in manuscript preparation and review. JMW had input in the conceptual and experimental design of the study, data analysis and manuscript editing. CBL contributed to conceptual and experimental design of the study and manuscript writing and review. JM conceptualised the study, undertook the cell culture and bright field microscopy, supervised the isolation of perlecan and type VI collagen, interpreted experimental data, wrote and edited the manuscript coordinating all other author contributions and prepared the final version. All authors approved the final version of the manuscript. We wish to confirm that there are no known conflicts of interest associated with this publication and there has been no significant financial support for this work that could have influenced its outcome.

\section{References}

Bax DV, Mahalingam Y, Cain S, Mellody K, Freeman L, Younger K, Shuttleworth CA, Humphries MJ, Couchman JR, Kielty CM (2007) Cell adhesion to fibrillin-1: identification of an Arg-Gly-Asp-dependent synergy region and a heparin-binding site that regulates focal adhesion formation. J Cell Sci 120: 1383-1392.

Burg MA, Tillet E, Timpl R, Stallcup WB (1996) Binding of the NG2 proteoglycan to type VI collagen and other extracellular matrix molecules. J Biol Chem 271: 26110-26116.

Cain SA, Baldwin AK, Mahalingam Y, Raynal B, Jowitt TA, Shuttleworth CA, Couchman JR, Kielty CM (2008) Heparan sulfate regulates fibrillin-1 N- and C-terminal interactions. J Biol Chem 283: 27017-27027.

Cao L, Guilak F, Setton LA (2007) Three-dimensional morphology of the pericellular matrix of intervertebral disc cells in the rat. J Anat 211: 444-452.

Cao L, Guilak F, Setton LA (2009) Pericellular matrix mechanics in the anulus fibrosus predicted by a three- dimensional finite element model and in situ morphology. Cell Mol Bioeng 2: 306-319.

Cao L, Guilak F, Setton LA (2011) Three-dimensional finite element modeling of pericellular matrix and cell mechanics in the nucleus pulposus of the intervertebral disk based on in situ morphology. Biomech Model Mechanobiol 10: $1-10$.

Clendenon JL, Phillips CL, Sandoval RM, Fang S, Dunn KW (2002) Voxx: a PC-based, near real-time volume rendering system for biological microscopy. Am J Physiol Cell Physiol 282: C213-218.

Cortes D, Elliott DM (2014) The intervertebral disc: overview of disc mechanics In: Shapiro I, Risbud MV (eds) The Intervertebral Disc. Molecular and Structural Studies of the Disc in Health and Disease, Springer-Verlag, Vienna, pp 17-31.

Darling EM, Wilusz RE, Bolognesi MP, Zauscher S, Guilak F (2010) Spatial mapping of the biomechanical properties of the pericellular matrix of articular cartilage measured in situ via atomic force microscopy. Biophys J 98: $2848-2856$.

Davis MR, Andersson R, Severin J, de Hoon M, Bertin N, Baillie JK, Kawaji H, Sandelin A, Forrest AR, Summers KM, FANTOM Consortium (2014) Transcriptional profiling of the human fibrillin/LTBP gene family, key regulators of mesenchymal cell functions. Mol Genet Metab 112: 73-83.

Day JM, Olin AI, Murdoch AD, Canfield A, Sasaki T, Timpl R, Hardingham TE, Aspberg A (2004) Alternative splicing in the aggrecan G3 domain influences binding interactions with tenascin-C and other extracellular matrix proteins. J Biol Chem 279: 12511-12518.

Doane KJ, Howell SJ, Birk DE (1998) Identification and functional characterization of two type VI collagen receptors, alpha 3 beta 1 integrin and NG2, during avian corneal stromal development. Invest Ophthalmol Vis Sci 39: 263-275.

Feng H, Danfelter M, Stromqvist B, Heinegard D (2006) Extracellular matrix in disc degeneration. J Bone Joint Surg Am 88 Suppl 2: 25-29.

Fresquet M, Jowitt TA, Stephen LA, Ylostalo J, Briggs MD (2010) Structural and functional investigations of matrilin-1 A-domains reveal insights into their role in cartilage ECM assembly. J Biol Chem 285: 34048-34061.

Gruber HE, Hoelscher GL, Ingram JA, Bethea S, Hanley EN Jr (2015) Autophagy in the degenerating human intervertebral disc: in vivo molecular and morphological evidence, and induction of autophagy in cultured annulus cells exposed to proinflammatory cytokines-implications for disc degeneration. Spine 40: 773-782.

Guilak F, Alexopoulos LG, Upton ML, Youn I, Choi JB, Cao L, Setton LA, Haider MA (2006) The pericellular matrix as a transducer of biomechanical and biochemical signals in articular cartilage. Ann NY Acad Sci 1068: 498512.

Hansen U, Allen JM, White R, Moscibrocki C, Bruckner P, Bateman JF, Fitzgerald J (2012) WARP interacts with collagen VI-containing microfibrils in the pericellular matrix of human chondrocytes. PLoS One 7: e52793. 
Hayes AJ, Lord MS, Smith SM, Smith MM, Whitelock JM, Weiss AS, Melrose J (2011a) Colocalization in vivo and association in vitro of perlecan and elastin. Histochem Cell Biol 136: 437-454.

Hayes AJ, Smith SM, Gibson MA, Melrose J (2011b) Comparative immunolocalization of the elastin fiberassociated proteins fibrillin-1, LTBP-2, and MAGP-1 with components of the collagenous and proteoglycan matrix of the fetal human intervertebral disc. Spine 36: E1365-1372.

Hayes AJ, Smith SM, Melrose J (2013) Comparative immunolocalisation of fibrillin-1 and perlecan in the human foetal, and HS-deficient hspg2 exon 3 null mutant mouse intervertebral disc. Histochem Cell Biol 139: 1-11.

Hayes AJ, Gibson MA, Shu C, Melrose J (2014) Confocal microscopy demonstrates association of LTBP-2 in fibrillin-1 microfibrils and colocalisation with perlecan in the disc cell pericellular matrix. Tissue Cell 46: 185-197.

Hirani R, Hanssen E, Gibson MA (2007) LTBP-2 specifically interacts with the amino-terminal region of fibrillin-1 and competes with LTBP-1 for binding to this microfibrillar protein. Matrix Biol 26: 213-223.

Horikawa O, Nakajima H, Kikuchi T, Ichimura S, Yamada H, Fujikawa K, Toyama Y (2004) Distribution of type VI collagen in chondrocyte microenvironment: study of chondrons isolated from human normal and degenerative articular cartilage and cultured chondrocytes. J Orthop Sci 9: 29-36.

Hoy D, March L, Brooks P, Woolf A, Blyth F, Vos T, Buchbinder R (2010) Measuring the global burden of low back pain. Best Pract Res Clin Rheumatol 24: 155-165.

Hoy D, March L, Brooks P, Blyth F, Woolf A, Bain C, Williams G, Smith E, Vos T, Barendregt J, Murray C, Burstein R, Buchbinder R (2014a) The global burden of low back pain: estimates from the Global Burden of Disease 2010 study. Ann Rheum Dis 73: 968-974.

Hoy DG, Smith E, Cross M, Sanchez-Riera L, Buchbinder R, Blyth FM, Brooks P, Woolf AD, Osborne RH, Fransen M, Driscoll T, Vos T, Blore JD, Murray C, Johns N, Naghavi M, Carnahan E, March LM (2014b) The global burden of musculoskeletal conditions for 2010: an overview of methods. Ann Rheum Dis 73: 982-989.

Hubmacher D, Tiedemann K, Reinhardt DP (2006) Fibrillins: from biogenesis of microfibrils to signaling functions. Curr Top Dev Biol 75: 93-123.

Humzah MD, Soames RW (1988) Human intervertebral disc: structure and function. Anat Rec 220: 337-356.

Jordan CD, Charbonneau NL, Sakai LY (2006) Fibrillin microfibrils: connective tissue pathways that regulate shape and signaling. J Musculoskelet Neuronal Interact 6: 366367.

Jovanovic J, Takagi J, Choulier L, Abrescia NG, Stuart DI, van der Merwe PA, Mardon HJ, Handford PA (2007) AlphaVbeta6 is a novel receptor for human fibrillin-1. Comparative studies of molecular determinants underlying integrin-RGD affinity and specificity. J Biol Chem 282: 6743-6751.

Kan R, Shuen WH, Lung HL, Cheung AK, Dai W, Kwong DL, Ng WT, Lee AW, Yau CC, Ngan RK, Tung SY, Lung ML (2015) NF-kappaB p65 subunit is modulated by latent transforming growth factor-beta binding protein 2
(LTBP2) in nasopharyngeal carcinoma HONE1 and HK1 cells. PLoS One 10: e0127239.

Kermani HR, Hoboubati H, Esmaeili-Mahani S, Asadi-Shekaari M (2014) Induction of intervertebral disc cell apoptosis and degeneration by chronic unpredictable stress. J Neurosurg Spine 20: 578-584.

Kielty CM, Baldock C, Lee D, Rock MJ, Ashworth JL, Shuttleworth CA (2002a) Fibrillin: from microfibril assembly to biomechanical function. Philos Trans R Soc Lond B Biol Sci 357: 207-217.

Kielty CM, Sherratt MJ, Shuttleworth CA (2002b) Elastic fibres. J Cell Sci 115: 2817-2828.

Kielty CM, Wess TJ, Haston L, Ashworth JL, Sherratt MJ, Shuttleworth CA (2002c) Fibrillin-rich microfibrils: elastic biopolymers of the extracellular matrix. J Muscle Res Cell Motil 23: 581-596.

Kielty CM, Sherratt MJ, Marson A, Baldock C (2005) Fibrillin microfibrils. Adv Protein Chem 70: 405-436.

Knox S, Merry C, Stringer S, Melrose J, Whitelock J (2002) Not all perlecans are created equal: interactions with fibroblast growth factor (FGF) 2 and FGF receptors. J Biol Chem 277: 14657-14665.

Kuo YJ, Wu LC, Sun JS, Chen MH, Sun MG, Tsuang YH (2014) Mechanical stress-induced apoptosis of nucleus pulposus cells: an in vitro and in vivo rat model. J Orthop Sci 19: 313-322.

Kvist AJ, Johnson AE, Morgelin M, Gustafsson E, Bengtsson E, Lindblom K, Aszódi A, Fässler R, Sasaki T, Timpl R, Aspberg A (2006) Chondroitin sulfate perlecan enhances collagen fibril formation. Implications for perlecan chondrodysplasias. J Biol Chem 281: $33127-$ 33139.

Li B, Urban JP, Yu J (2012) The distribution of fibrillin-2 and LTBP-2, and their co-localisation with fibrillin-1 in adult bovine tail disc. J Anat 220: 164-172.

Ma KG, Shao ZW, Yang SH, Wang J, Wang BC, Xiong LM, Wu Q, Chen SF (2013) Autophagy is activated in compression-induced cell degeneration and is mediated by reactive oxygen species in nucleus pulposus cells exposed to compression. Osteoarthritis Cartilage 21: 2030-2038.

Maniadakis N, Gray A (2000) The economic burden of back pain in the UK. Pain 84: 95-103.

Mariko B, Ghandour Z, Raveaud S, Quentin M, Usson Y, Verdetti J, Huber P, Kielty C, Faury G (2010) Microfibrils and fibrillin-1 induce integrin-mediated signaling, proliferation and migration in human endothelial cells. Am J Physiol Cell Physiol 299: C977-987.

McGowan SE, Holmes AJ, Mecham RP, Ritty TM (2008) Arg-Gly-Asp-containing domains of fibrillins-1 and -2 distinctly regulate lung fibroblast migration. Am J Respir Cell Mol Biol 38: 435-445.

McLeod MA, Wilusz RE, Guilak F (2013) Depthdependent anisotropy of the micromechanical properties of the extracellular and pericellular matrices of articular cartilage evaluated via atomic force microscopy. J Biomech 46: 586-592.

Melrose J, Roughley P, Knox S, Smith S, Lord M, Whitelock J (2006) The structure, location, and function of perlecan, a prominent pericellular proteoglycan of fetal, postnatal, and mature hyaline cartilages. J Biol Chem 281: 36905-36914. 
Melrose J, Smith SM, Appleyard RC, Little CB (2008) Aggrecan, versican and type VI collagen are components of annular translamellar crossbridges in the intervertebral disc. Eur Spine J 17: 314-324.

Menz C, Parsi MK, Adams JR, Sideek MA, Kopecki Z, Cowin AJ, Gibson MA (2015) LTBP-2 Has a single highaffinity binding site for FGF-2 and blocks FGF-2-induced cell proliferation. PLoS One 10: e0135577.

Midwood KS, Schwarzbauer JE (2002) Elastic fibers: building bridges between cells and their matrix. Curr Biol 12: R279-281.

Nishiyama A, Stallcup WB (1993) Expression of NG2 proteoglycan causes retention of type VI collagen on the cell surface. Mol Biol Cell 4: 1097-1108.

Olin AI, Morgelin M, Sasaki T, Timpl R, Heinegard D, Aspberg A (2001) The proteoglycans aggrecan and versican form networks with fibulin-2 through their lectin domain binding. J Biol Chem 276: 1253-1261.

Parsi MK, Adams JR, Whitelock J, Gibson MA (2010) LTBP-2 has multiple heparin/heparan sulfate binding sites. Matrix Biol 29: 393-401.

Poole CA, Ayad S, Gilbert RT (1992) Chondrons from articular cartilage. V. Immunohistochemical evaluation of type VI collagen organisation in isolated chondrons by light, confocal and electron microscopy. J Cell Sci 103: 1101-1110.

Ramirez F, Dietz HC (2007) Fibrillin-rich microfibrils: Structural determinants of morphogenetic and homeostatic events. J Cell Physiol 213: 326-330.

Ramirez F, Sakai LY, Rifkin DB, Dietz HC (2007) Extracellular microfibrils in development and disease. Cell Mol Life Sci 64: 2437-2446.

Ramirez F, Carta L, Lee-Arteaga S, Liu C, Nistala H, Smaldone S (2008) Fibrillin-rich microfibrils - structural and instructive determinants of mammalian development and physiology. Connect Tissue Res 49: 1-6.

Ritty TM, Ditsios K, Starcher BC (2002) Distribution of the elastic fiber and associated proteins in flexor tendon reflects function. Anat Rec 268: 430-440.

Schollum ML, Appleyard RC, Little CB, Melrose J (2010) A detailed microscopic examination of alterations in normal anular structure induced by mechanical destabilization in an ovine model of disc degeneration. Spine 35: 1965-1973.

Shapiro I, Risbud, MV (2014) Introduction to the structure, function and comparative anatomy of the vertebrae and the intervertebral disc. In: Shapiro I, Risbud MV (eds) The Intervertebral Disc. Molecular and Structural Studies of the Disc in Health and Disease, Springer-Verlag, Vienna, pp 3-16.

Sherratt MJ, Baldock C, Haston JL, Holmes DF, Jones CJ, Shuttleworth CA, Wess TJ, Kielty CM (2003) Fibrillin microfibrils are stiff reinforcing fibres in compliant tissues. J Mol Biol 332: 183-193.

Shu C, Hughes C, Smith SM, Smith MM, Hayes A, Caterson B, Little CB, Melrose J (2013a) The ovine newborn and human foetal intervertebral disc contain perlecan and aggrecan variably substituted with native 7D4 CS sulphation motif: spatiotemporal immunolocalisation and co-distribution with notch-1 in the human foetal disc. Glycoconj J 30: 717-725.
Shu C, Smith SS, Little CB, Melrose J (2013b) Comparative immunolocalisation of perlecan, heparan sulphate, fibroblast growth factor-18, and fibroblast growth factor receptor-3 and their prospective roles in chondrogenic and osteogenic development of the human foetal spine. Eur Spine J 22: 1774-1784.

Sideek MA, Menz C, Parsi MK, Gibson MA (2014) LTBP-2 competes with tropoelastin for binding to fibulin-5 and heparin, and is a negative modulator of elastinogenesis. Matrix Biol 34: 114-123.

Smith SM, Whitelock JM, Iozzo RV, Little CB, Melrose $\mathrm{J}$ (2009) Topographical variation in the distributions of versican, aggrecan and perlecan in the foetal human spine reflects their diverse functional roles in spinal development. Histochem Cell Biol 132: 491-503.

Smith SM, Shu C, Melrose J (2010) Comparative immunolocalisation of perlecan with collagen II and aggrecan in human foetal, newborn and adult ovine joint tissues demonstrates perlecan as an early developmental chondrogenic marker. Histochem Cell Biol 134: 251-263.

Stallcup WB, Dahlin K, Healy P (1990) Interaction of the NG2 chondroitin sulfate proteoglycan with type VI collagen. J Cell Biol 111: 3177-3188.

Tillet E, Gential B, Garrone R, Stallcup WB (2002) NG2 proteoglycan mediates beta1 integrin-independent cell adhesion and spreading on collagen VI. J Cell Biochem 86: $726-736$.

Tsuruga E, Sato A, Ueki T, Nakashima K, Nakatomi Y, Ishikawa H, Yajima T, Sawa Y (2009) Integrin alphavbeta3 regulates microfibril assembly in human periodontal ligament cells. Tissue Cell 41: 85-89.

Tulla M, Pentikainen OT, Viitasalo T, Käpylä J, Impola U, Nykvist P, Nissinen L, Johnson MS, Heino J (2001) Selective binding of collagen subtypes by integrin alpha 1I, alpha 2I, and alpha 10I domains. J Biol Chem 276: 48206-48212.

Vo NV, Hartman RA, Patil PR, Risbud MV, Kletsas D, Iatridis JC, Hoyland JA, Le Maitre CL, Sowa GA, Kang JD (2016) Molecular mechanisms of biological aging in intervertebral discs. J Orthop Res doi: 10.1002/jor.23195.

Vos T, Flaxman AD, Naghavi M, Lozano R, Michaud C, Ezzati M, Shibuya K, Salomon JA, Abdalla S, Aboyans V, Abraham J, Ackerman I, Aggarwal R, Ahn SY, Ali MK, Alvarado M, Anderson HR, Anderson LM, Andrews KG, Atkinson C, Baddour LM, Bahalim AN, Barker-Collo S, Barrero LH, Bartels DH, Basáñez MG, Baxter A, Bell ML, Benjamin EJ, Bennett D, Bernabé E, Bhalla K, Bhandari B, Bikbov B, Bin Abdulhak A, Birbeck G, Black JA, Blencowe H, Blore JD, Blyth F, Bolliger I, Bonaventure A, Boufous S, Bourne R, Boussinesq M, Braithwaite T, Brayne C, Bridgett L, Brooker S, Brooks P, Brugha TS, Bryan-Hancock C, Bucello C, Buchbinder R, Buckle G, Budke CM, Burch M, Burney P, Burstein R, Calabria B, Campbell B, Canter CE, Carabin H, Carapetis J, Carmona L, Cella C, Charlson F, Chen H, Cheng AT, Chou D, Chugh SS, Coffeng LE, Colan SD, Colquhoun S, Colson KE, Condon J, Connor MD, Cooper LT, Corriere M, Cortinovis M, de Vaccaro KC, Couser W, Cowie BC, Criqui MH, Cross M, Dabhadkar KC, Dahiya M, Dahodwala N, DamsereDerry J, Danaei G, Davis A, De Leo D, Degenhardt L, Dellavalle R, Delossantos A, Denenberg J, Derrett S, Des 
Jarlais DC, Dharmaratne SD, Dherani M, Diaz-Torne C, Dolk H, Dorsey ER, Driscoll T, Duber H, Ebel B, Edmond K, Elbaz A, Ali SE, Erskine H, Erwin PJ, Espindola P, Ewoigbokhan SE, Farzadfar F, Feigin V, Felson DT, Ferrari A, Ferri CP, Fèvre EM, Finucane MM, Flaxman S, Flood L, Foreman K, Forouzanfar MH, Fowkes FG, Franklin R, Fransen M, Freeman MK, Gabbe BJ, Gabriel SE, Gakidou E, Ganatra HA, Garcia B, Gaspari F, Gillum RF, Gmel G, Gosselin R, Grainger R, Groeger J, Guillemin F, Gunnell D, Gupta R, Haagsma J, Hagan H, Halasa YA, Hall W, Haring D, Haro JM, Harrison JE, Havmoeller R, Hay RJ, Higashi H, Hill C, Hoen B, Hoffman H, Hotez PJ, Hoy D, Huang JJ, Ibeanusi SE, Jacobsen KH, James SL, Jarvis D, Jasrasaria R, Jayaraman S, Johns N, Jonas JB, Karthikeyan G, Kassebaum N, Kawakami N, Keren A, Khoo JP, King CH, Knowlton LM, Kobusingye O, Koranteng A, Krishnamurthi R, Lalloo R, Laslett LL, Lathlean T, Leasher JL, Lee YY, Leigh J, Lim SS, Limb E, Lin JK, Lipnick M, Lipshultz SE, Liu W, Loane M, Ohno SL, Lyons R, Ma J, Mabweijano J, MacIntyre MF, Malekzadeh R, Mallinger L, Manivannan S, Marcenes W, March L, Margolis DJ, Marks GB, Marks R, Matsumori A, Matzopoulos R, Mayosi BM, McAnulty JH, McDermott MM, McGill N, McGrath J, Medina-Mora ME, Meltzer M, Mensah GA, Merriman TR, Meyer AC, Miglioli V, Miller M, Miller TR, Mitchell PB, Mocumbi AO, Moffitt TE, Mokdad AA, Monasta L, Montico M, Moradi-Lakeh M, Moran A, Morawska L, Mori R, Murdoch ME, Mwaniki MK, Naidoo K, Nair MN, Naldi L, Narayan KM, Nelson PK, Nelson RG, Nevitt MC, Newton CR, Nolte S, Norman P, Norman R, O’Donnell M, O'Hanlon S, Olives C, Omer SB, Ortblad K, Osborne R, Ozgediz D, Page A, Pahari B, Pandian JD, Rivero AP, Patten SB, Pearce N, Padilla RP, Perez-Ruiz F, Perico N, Pesudovs K, Phillips D, Phillips MR, Pierce K, Pion S, Polanczyk GV, Polinder S, Pope CA 3rd, Popova S, Porrini E, Pourmalek F, Prince M, Pullan RL, Ramaiah KD, Ranganathan D, Razavi H, Regan M, Rehm JT, Rein DB, Remuzzi G, Richardson K, Rivara FP, Roberts T, Robinson C, De Leòn FR, Ronfani L, Room R, Rosenfeld LC, Rushton L, Sacco RL, Saha S, Sampson U, Sanchez-Riera L, Sanman E, Schwebel DC, Scott JG, Segui-Gomez M, Shahraz S, Shepard DS, Shin H, Shivakoti R, Singh D, Singh GM, Singh JA, Singleton J, Sleet DA, Sliwa K, Smith E, Smith JL, Stapelberg NJ, Steer A, Steiner T, Stolk WA, Stovner LJ, Sudfeld C, Syed S, Tamburlini G, Tavakkoli M, Taylor HR, Taylor JA, Taylor WJ, Thomas B, Thomson WM, Thurston GD, Tleyjeh IM, Tonelli M, Towbin JA, Truelsen T, Tsilimbaris MK, Ubeda C, Undurraga EA, van der Werf MJ, van Os J, Vavilala MS, Venketasubramanian N, Wang M, Wang W, Watt K, Weatherall DJ, Weinstock MA, Weintraub R, Weisskopf MG, Weissman MM, White RA, Whiteford H, Wiersma ST, Wilkinson JD, Williams HC, Williams SR, Witt E, Wolfe F, Woolf AD, Wulf S, Yeh PH, Zaidi AK, Zheng ZJ, Zonies D, Lopez AD, Murray CJ, AlMazroa MA, Memish ZA (2012) Years lived with disability (YLDs) for 1160 sequelae of 289 diseases and injuries 1990-2010: a systematic analysis for the Global Burden of Disease Study 2010. Lancet 380: 2163-2196.
Walker BF, Muller R, Grant WD (2003) Low back pain in Australian adults: the economic burden. Asia Pac J Public Health 15: 79-87.

Wang F, Cai F, Shi R, Wang XH, Wu XT (2016) Aging and age related stresses: a senescence mechanism of intervertebral disc degeneration. Osteoarthritis Cartilage 24: 398-408.

Whitelock JM, Melrose J, Iozzo RV (2008) Diverse cell signaling events modulated by perlecan. Biochemistry 47: 11174-11183.

Wiberg C, Klatt AR, Wagener R, Paulsson M, Bateman JF, Heinegård D, Mörgelin M (2003) Complexes of matrilin-1 and biglycan or decorin connect collagen VI microfibrils to both collagen II and aggrecan. J Biol Chem 278: 37698-37704.

Wilusz RE, Defrate LE, Guilak F (2012)A biomechanical role for perlecan in the pericellular matrix of articular cartilage. Matrix Biol 31: 320-327.

Yu J (2002) Elastic tissues of the intervertebral disc. Biochem Soc Trans 30: 848-852.

Yu J, Winlove PC, Roberts S, Urban JP (2002) Elastic fibre organization in the intervertebral discs of the bovine tail. J Anat 201: 465-475.

Yu J, Fairbank JC, Roberts S, Urban JP (2005) The elastic fiber network of the anulus fibrosus of the normal and scoliotic human intervertebral disc. Spine 30: 18151820.

Yu J, Tirlapur U, Fairbank J, Handford P, Roberts S, Winlove CP, Cui Z, Urban J (2007) Microfibrils, elastin fibres and collagen fibres in the human intervertebral disc and bovine tail disc. J Anat 210: 460-471.

Yu J, Schollum ML, Wade KR, Broom ND, Urban JP (2015) A detailed examination of the elastic network leads to a new understanding of annulus fibrosus organization. Spine 40: 1149-1157.

Zelenski NA, Leddy HA, Sanchez-Adams J, Zhang J, Bonaldo P, Liedtke W, Guilak F (2015) Collagen VI regulates pericellular matrix properties, chondrocyte swelling, and mechanotransduction in articular cartilage. Arthritis Rheumatol 67: 1286-1294.

\section{Discussion with Reviewers}

Reviewer I: Since collagen VI is ubiquitously expressed, is there evidence in other tissues that collagen VI is associated with elastic recoil properties in other tissues.

Authors: We believe these recoil properties are really a function of the elastin networks type VI collagen is attached to in the tissue, thus this probably occurs in any tissue containing these networks and type VI collagen. However, there are some surprising tissue locations where type VI occurs such as the hypertrophic cells of the ovine vertebral growth plate (Melrose et al., 2002; Melrose et al., 2016) and trabecular bone, and it remains to be determined if elastin networks are also important in these tissues. Although elastin is a relatively minor component of IVD tissues, elastin fibres are nevertheless prominent in the IVD running both within and between collagenous 
lamellae of the $\mathrm{AF}$ and in specialised structures such as the translamellar cross bridge. In articular cartilage, elastin fibres occur as an interritorial network in the surface zone and pericellular matrix. An important question is why do elastin and type VI collagen fibrils occur so prominently in tissues containing dense collagenous fibrillar arrays which provide the predominant biomechanical character of that tissue, namely mechanical strength under tensional loading. Type VI collagen fibrils are also distributed in close proximity to these elastic and collagen fibrillar arrangements; however, they have not been ascribed a mechanical role similar to that of the fibrillar collagens. Rather, the type VI collagen networks appear to act as a linker of functional ECM components such as the collagen fibrillar assemblies, HA-aggrecan macromolecular arrays, and elastin networks. Thus an interplay exists between these components to provide IVD tissue with its ability to withstand tensional and compressional forces. Further, this extended type VI collagen-fibrillar collagen-HA-aggrecanelastin network provides a means of dissipating mechanical forces throughout the ECM, preventing focal overload of individual collagen fibrils or fibre bundles. Thus, a synergy exists between collagen fibrillar arrangements, elastin and type VI collagen in connective tissues. Various models have attempted to describe the interactive associations between these entities. Elastin fibres have been proposed to have roles during low tissue deformation, acting as a buffering component prior to recruitment of collagen fibres which resist tensional forces at high tissue deformation. These forces are dynamic, thus the elastin fibres are again recruited once the collagen fibres are unloaded and relaxed; however, they are relatively inextensible and the elastin fibrils return these to their original pre-stressed dimensions. Thus a recoil property can be envoked for the elastin-type VI collagen assemblies in the tissue. These interrelationships are deduced from electron microscopy and immunolocalisation data and functional biophysical studies on isolated macromolecular components. Direct evidence to support the roles of the isolated components at the fibrillar and microfibrillar level is incomplete, due to their small size and the complexity of the heterogeneous environment of the elastin microfibrils/fibrils. Atomic force microscopy is, however, providing invaluable information on the role of type VI collagen and perlecan in tissues, but these need to be considered in relation to the other ECM components they are attached to. Like elastin, collagen VI forms distinct microfibrillar ECM networks and anchors interstitial structures, such as nerves, blood vessels and larger collagen fibrils. Collagen VI also mediates cell-cell communication and matrix assembly. The von Willebrand domains of type VI collagen facilitate its interaction with cells and it is also interactive with a number of integrins and CSPG4. Blood vessels are subject to pulsatile forces, thus the type VI ECM experiences high shear due to blood flow followed by a relaxed state between heart beats. So it is likely that elastin-type VI collagen also provides resiliency to these and related tissues.

Reviewer II: Fig. 2 nicely shows distinct patterns of collagen VI and perlecan that are only partially colocalised. Do the authors have any hypotheses on the relative interaction of these components with the cells, and whether the regional distribution provides any cues as to the function of these molecules in cell-matrix interactions? Authors: Our original title to the paper suggested roles for type VI collagen and perlecan in matrix assembly, mechanotransduction and cell-ECM signalling. The title has been amended in the revised manuscript; however, these remain as areas where we believe type VI collagen and perlecan have important roles to play. Many studies have demonstrated the ECM and pericellular matrix components with which perlecan can interact. Perlecan also interacts with $\alpha 5 \beta 1$ and $\alpha 2 \beta 1$ integrin. The latter involves the endorepellin domain of perlecan which has antiangiogenic properties when released from the core protein. These interactions anchor the cell within the ECM and equip it with mechanoresponsiveness through perlecantype VI collagen networks with other ECM components. Type VI collagen acts as a linker network between the pericellular matrix and collagen-HA-aggrecan-elastin networks in the interstitial matrix providing an extended remote sensory system for mechanotransductive feedback effects facilitating cell-matrix communication and appropriate responses by the cell which maintain tissue homeostasis.

\section{Additional References}

Melrose J, Smith S, Knox S, Whitelock J (2002) Perlecan, the multidomain HS-proteoglycan of basement membranes, is a prominent pericellular component of ovine hypertrophic vertebral growth plate and cartilaginous endplate chondrocytes. Histochem Cell Biol 118: 269-280.

Melrose J, Shu C, Whitelock JM, Lord MS (2016) The cartilage extracellular matrix as a transient developmental scaffold for growth plate maturation. Matrix Biol 52-54: 363-383.

Editor's Note: Scientific Editor in charge of the paper: Brian Johnstone. 